\title{
Stability Charts for Pseudostatic Stability Analysis of Rock Slopes Using the Nonlinear Hoek-Brown Strength Reduction Technique
}

\author{
Chaowei Sun (D), ${ }^{1}$ Junrui Chai, ${ }^{1,2}$ Tao Luo, ${ }^{2}$ Zengguang $X{ }^{2}{ }^{2}$ Yuan Qin, ${ }^{2}$ \\ Xiaosa Yuan, ${ }^{1}$ and Bin $\mathrm{Ma}^{1}$ \\ ${ }^{1}$ Shaanxi Key Laboratory of Safety and Durability of Concrete Structures, Xijing University, Xi'an 710123, China \\ ${ }^{2}$ State Key Laboratory Base of Ecohydraulics Engineering in Northwest Arid Area, Xi'an University of Technology, \\ Xi'an 710048, China
}

Correspondence should be addressed to Chaowei Sun; chao_wei_106@126.com

Received 9 April 2020; Revised 1 July 2020; Accepted 8 July 2020; Published 6 August 2020

Academic Editor: Chunshun Zhang

Copyright (C) 2020 Chaowei Sun et al. This is an open access article distributed under the Creative Commons Attribution License, which permits unrestricted use, distribution, and reproduction in any medium, provided the original work is properly cited.

\begin{abstract}
This paper presents a set of stability charts for the stability assessment of rock slopes that satisfy the Hoek-Brown (HB) criterion under various seismic loading conditions. The nonlinear Hoek-Brown strength reduction technique is used to conduct pseudostatic stability analysis of rock slopes subjected to horizontal seismic excitation. Based on an extensive parametric study, first, a set of stability charts with a slope angle of $\beta=45^{\circ}$ under static and pseudostatic conditions are proposed by using ABAQUS 6.10 software. Second, the slope angle weighting factor $\left(f_{\beta}\right)$ and the seismic weighting factor $\left(f_{k h}\right)$ are adopted to characterize the influence of slope angle $(\beta)$ and horizontal seismic acceleration coefficient $\left(k_{h}\right)$ on the rock slope stability. Finally, the reliability of the proposed charts was validated by three typical examples and two case studies, and the results show that the values of the factor of safety (FOS) obtained from the proposed charts are consistent with the values from other methods. The proposed charts provide an efficient and convenient way to determine the FOS of rock slopes directly from the rock mass properties $\left(\gamma\right.$ and $\left.\sigma_{\mathrm{ci}}\right)$, the HB parameters $\left(m_{\mathrm{i}}\right.$ and GSI), the slope geometry $(H$ and $\beta)$, and the horizontal seismic coefficients $\left(k_{h}\right)$.
\end{abstract}

\section{Introduction}

In regions of high seismic intensity, earthquakes are a major cause of man-made and natural slope failures. Therefore, conducting stability analyses of rock slopes subjected to the seismic conditions has been regarded as an important and difficult issue in civil and mining engineering. Stability charts provide an efficient and convenient way for preliminary and rapid slope stability evaluation, and they have been routinely applied in practical application to calculate the factor of safety (FOS) of a slope. Since Taylor [1] put forward a set of stability charts for soil slopes for the first time, many attempts have been made to develop such charts for rock or soil slopes, e.g., Gens et al. [2], Baker [3], Li et al. $[4,5]$, Michalowski [6, 7], Steward et al. [8], Gao et al. [9], Eid [10], and Sun et al. [11]. However, these charts are based on the commonly used Mohr-Coulomb (MC) failure criterion and need the shear strength parameters of cohesion $c$ and internal friction angle $\varphi$ for slope stability analysis. However, the rock masses are discontinuous and inhomogeneous media characterized by intact rock and artificially or naturally occurring discontinuities such as joints, faults, bedding planes, and fractures. Therefore, the linear MC failure criterion is generally not applicable to describe the failure envelope of the rock mass [12-15].

Since the HB failure criterion, originally presented by Hoek and Brown [16], reflects the nonlinear nature of the rock mass strength, it is currently one of the most commonly used failure criteria to predict the strength of intact rock (Group I) and rock masses with heavy joints or discontinuities (Group III), as shown in Figure 1. The latest version is the generalized Hoek-Brown (GHB) criterion proposed by Hoek et al. [17] and is expressed as follows: 


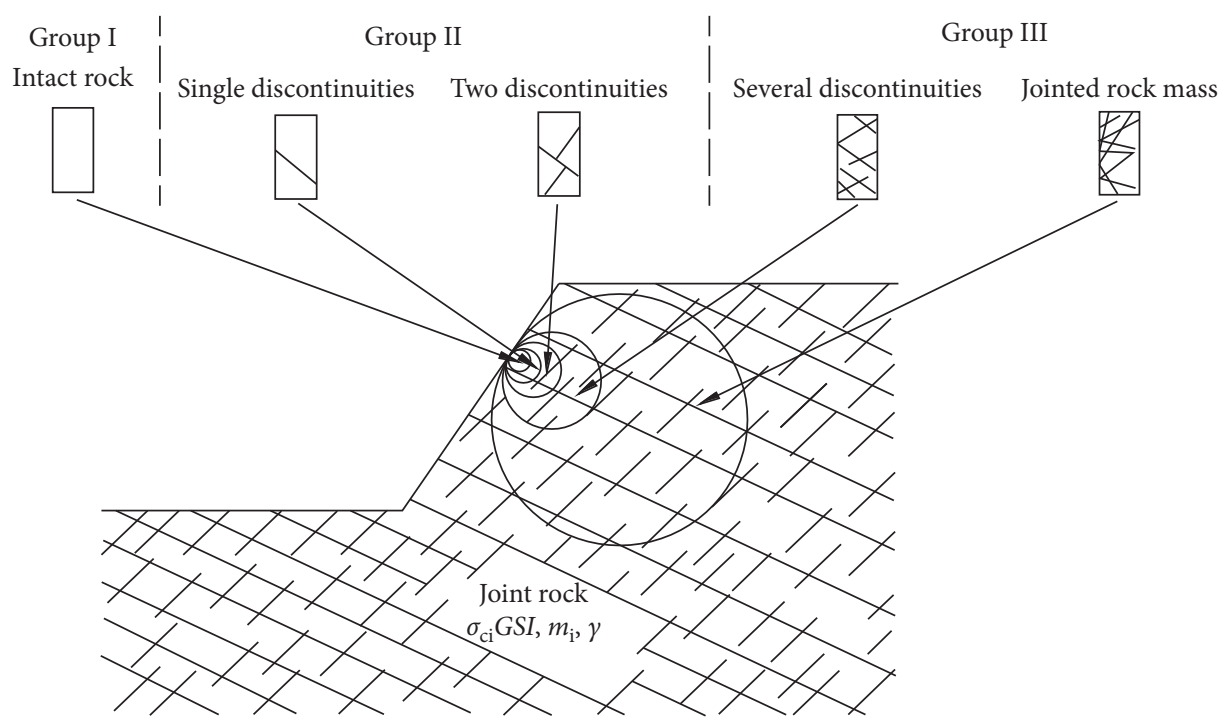

Figure 1: Applicability of the HB failure criteria for the rock slope [17].

$$
\sigma_{1}=\sigma_{3}+\sigma_{c i}\left(m_{b} \frac{\sigma_{3}}{\sigma_{c i}}+s\right)^{\alpha}
$$

where $\sigma_{\mathrm{ci}}$ is the uniaxial compressive strength of the intact rock and

$$
\begin{aligned}
m_{b} & =m_{i} \exp \left(\frac{G S I-100}{28-14 D}\right), \\
s & =\exp \left(\frac{G S I-100}{9-3 D}\right), \\
\alpha & =\frac{1}{2}+\frac{1}{6}\left[\exp \left(-\frac{G S I}{15}\right)-\exp \left(-\frac{20}{3}\right)\right] .
\end{aligned}
$$

Based on (2) to (4), the input properties of $s, \alpha$, and $m_{\mathrm{b}}$ rely on the geological strength index (GSI) depending on the degree of fracturing of the rock mass. The GSI values range from 5 for extremely fractured rock masses to 100 for intact rock masses. $m_{\mathrm{i}}$ is an index related to the type of rock, and its value varies from 1 to 35 , representing different magnitudes of rock hardness. $D$ is the disturbance factor, ranging from 0 for undisturbed in situ rock masses to 1.0 for disturbed rock masses. Guidelines on how to obtain the values of GSI and $m_{\mathrm{i}}$ can be found in Hoek and Bray [18], Marinos and Hoek [19], and Hoek et al. [20]. In this research, the value of $D=0$ is used in the analyses of rock slope stability.

Currently, the strength reduction method (SRM) is very attractive for solution of slope stability problem. Since this method was first introduced by Zienkiewicz et al. [21], it has been commonly accepted and employed in practice by many geotechnical engineers and researchers because there are two major advantages when SRM is applied to analyze the slope stability: (i) the SRM can not only consider the stress-strain behavior but also simulate the progressive failure mode of the slope with complicated geometric shapes and loading conditions; and (ii) the critical failure surface, including the location and shape, can be located automatically while the FOS is obtained simultaneously [22]. Therefore, the purpose of the present research is to conduct a pseudostatic stability analysis of rock slopes based on the nonlinear $\mathrm{HB}$ strength reduction technique presented in our previous study [23] and to propose the stability charts for evaluating the stability of rock slopes that satisfy the $\mathrm{HB}$ criterion under the seismic condition. A simple method consisting of locating the tangent of the $\mathrm{HB}$ envelope and introducing the instantaneous $\mathrm{MC}$ shear strength parameters is used to implement the nonlinear $\mathrm{HB}$ strength reduction technique. The PS stability analysis in this paper only considers the effect of horizontal seismic loads, and the vertical seismic loads are not considered. However, the proposed charts provide a convenient way to determine the FOS of rock slopes directly from rock mass properties $\left(\gamma\right.$ and $\sigma_{\mathrm{ci}}$ ), the HB parameters $\left(m_{\mathrm{i}}\right.$ and GSI), slope geometry $(H$ and $\beta)$, and horizontal seismic coefficients $\left(k_{h}\right)$.

\section{Review of Existing Stability Charts for Rock Slopes Based on the HB Criterion}

It remains difficult to develop stability charts on the basis of the $\mathrm{HB}$ failure criterion since at least six parameters $\left(\sigma_{\mathrm{ci}}, m_{\mathrm{i}}\right.$, $\gamma, H, \beta$, and GSI) are included in stability analysis for a rock slope under the condition of $D=0$. Based on our literature review, only the stability charts proposed by Li et al. [24-26], Carranza-Torres [27], Jiang et al. [28], and Shen et al. [29] can be applied to obtain the FOS directly from the HB failure criterion. Carranza-Torres [27] used the simplified Bishop method to analyze the rock slope stability and found that, for a given slope with $\alpha=0.5$, the FOS is related only to the three independent parameters of $\overline{\gamma H}, s / m_{b}^{2}$, and $\beta$. However, these charts are limited to the use of stability estimation of a rock slope with specified values of $\alpha=0.5$ and $\beta=45^{\circ}$. Recently, based on the limit equilibrium method (LEM), Shen et al. [29] first proposed a new chart-based stability analysis method for rock slopes using the HB criterion (see (5)) by introducing two weighting factors of $f_{D}$ and $f_{\beta}$ (see (6)) to examine the influence of the disturbance factor $D$ and the 
slope angle $\beta$ on the stability of rock slopes. However, these chart solutions were suitable for stability analysis of rock slopes under static condition, and the seismic effects were not considered in their studies:

$$
\begin{aligned}
\mathrm{FOS} & =\mathrm{FOS}_{45^{\circ}} \times f_{\beta} \times f_{D}, \\
f_{\beta} & =2.66 e^{-0.022 \beta}(0<\mathrm{FOS}<4) .
\end{aligned}
$$

The pseudostatic (PS) approach is a widely adopted and accepted technique in engineering practice and has been employed to investigate the earthquake effects on rock slope stability [30-37]. Based on the PS method, Li et al. [25] first used the limit analysis method (LAM) to develop the stability charts for seismic stability assessment of the rock slopes directly based on the HB failure criterion. The definition of the dimensionless stability number $(N)$ used in their study is shown in

$$
N=\frac{\sigma_{c i}}{\gamma \operatorname{HFOS}_{\mathrm{LAM}}}
$$

where FOS $_{\text {LAM }}$ is the FOS calculated by the LAM. The representative seismic stability charts for a rock slope with $\beta=45^{\circ}$ presented by Li et al. [25] are shown in Figure 2. A narrow range of the dimensionless stability numbers has been bounded, so the average values of $N$ are used to develop such charts for simplicity. Based on these charts, the stability number $N$ is obtained when the parameters of GSI and $m_{\mathrm{i}}$ are given under the condition of $D=0$. Then, the value of $N$ is adopted to calculate the FOS using (7). The values of

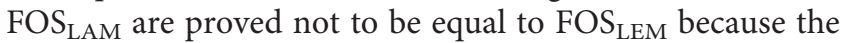
definition of FOS $_{\text {LAM }}$ differs from the definition of FOS $_{\text {LEM }}$ in slope limit equilibrium analysis $[23,29,38]$.

\section{Method of Analysis}

3.1. Nonlinear Strength Reduction Technique for HB Criterion. In the present study, to apply the $\mathrm{HB}$ failure criterion in conjunction with the strength reduction technique to pseudostatic stability analysis of rock slopes, the instantaneous MC shear strength parameters (the instantaneous internal friction angle $\varphi$ and instantaneous cohesion $c$ ) are obtained by locating the tangent of the HB envelope under a normal stress $\sigma_{n}$, as illustrated in Figure 3. Then, the slope of the tangent to the HB failure envelope yields the value of the instantaneous $\varphi$, and the intercept with $\tau$ axis gives the value of the instantaneous $c$. As shown in Figure 3, if the element stress state $\left(\sigma_{1}, \sigma_{3}\right)$ is given and described by the MC failure criterion, the corresponding values of the instantaneous $\varphi$ and $c$ can be obtained by the following equation [15]:

$$
\frac{\sigma_{n}}{\sigma_{c i}}=\frac{\sigma_{3 i}}{\sigma_{c i}}+\frac{1}{2}\left(m_{b} \frac{\sigma_{3}}{\sigma_{c i}}+s\right)^{\alpha}\left[1-\frac{\alpha m_{b}\left(m_{b}\left(\sigma_{3} / \sigma_{c i}\right)+s\right)^{\alpha-1}}{2+\alpha m_{b}\left(m_{b}\left(\sigma_{3} / \sigma_{c i}\right)+s\right)^{\alpha-1}}\right],
$$

$$
\frac{\tau_{s}}{\sigma_{c i}}=\left(m_{b} \frac{\sigma_{3}}{\sigma_{c i}}+s\right)^{\alpha} \frac{\sqrt{1+\alpha m_{b}\left(m_{b}\left(\sigma_{3} / \sigma_{c i}\right)+s\right)^{\alpha-1}}}{2+\alpha m_{b}\left(m_{b}\left(\sigma_{3} / \sigma_{c i}\right)+s\right)^{\alpha-1}}
$$

$$
\begin{gathered}
\varphi_{i}=\arcsin \left[1-\frac{2}{2+\alpha m_{b}\left(m_{b}\left(\sigma_{3 i} / \sigma_{c i}\right)+s\right)^{\alpha-1}}\right], \\
c_{i}=\tau_{s}-\sigma_{n} \tan \varphi_{i} .
\end{gathered}
$$

For the implementation of the nonlinear $\mathrm{HB}$ strength reduction technique, first, the grid elements are generated for the numerical slope model. When the basic parameters, boundary conditions, and loading are input and set accurately, the stress state of each element in the slope model can be obtained by conducting the elastoplastic analysis. Then, each element within the slope model is considered to satisfy the instantaneous MC failure envelope, and the instantaneous $\varphi$ and $c$ corresponding to different element stress states can be determined based on (8) to (11). In the present study, the estimation of the instantaneous MC strength parameters from the $\mathrm{HB}$ failure criterion is combined with the shear strength reduction technique for stability analysis of a rock slope using the finite element software ABAQUS 6.10. More details about the implementation of the nonlinear $\mathrm{HB}$ strength reduction technique are given in the latest research [23].

3.2. Pseudostatic Approach. In the PS approach, the earthquake load is replaced by an equivalent static force, and its magnitude is expressed as a product of horizontal or vertical seismic coefficients $\left(k_{h}\right.$ and $\left.k_{v}\right)$ and the weight of the soil or rock mass. Although it is generally recognized that the PS approach is conservative, the method is commonly employed in research as a result of its simplicity and effectiveness. In addition, currently, the slope design is often more concerned about the horizontal seismic effect in slope PS stability analysis. Therefore, this research emphasizes the analysis of the earthquake effects on rock slope stability based on various horizontal seismic coefficients. For the purpose of obtaining a reliable horizontal seismic coefficient for a given site, Figure 4 presented in the California Division of Mines and Geology [39] gives the design suggestions for pseudostatic analysis. As Figure 4 shows, the values of $k_{h}$ range from 0 to 0.375 within the range of a recommended pseudostatic safety factor. Therefore, the horizontal seismic coefficients varying between $k_{h}=0$ and $k_{h}=0.3$ are used in the present paper.

3.3. Problem Definition. Figure 5 shows the sketch of the definition for the pseudostatic stability analysis of rock slopes based on the HB failure criterion. In the present study, all the slope cases are assumed to have heavily jointed or fractured rock masses such as Group III in Figure 1, which are thus considered as isotropic and homogeneous throughout the slope. In this section, we carry out a parametric study on the problem presented and discuss the relationship between the FOS and the related seven input parameters such as the $\mathrm{HB}$ parameters $\left(m_{\mathrm{i}}\right.$ and GSI), rock mass properties $\left(\gamma\right.$ and $\left.\sigma_{\mathrm{ci}}\right)$, slope geometry $(\beta$ and $H)$, and horizontal seismic coefficients $\left(k_{h}\right)$. 


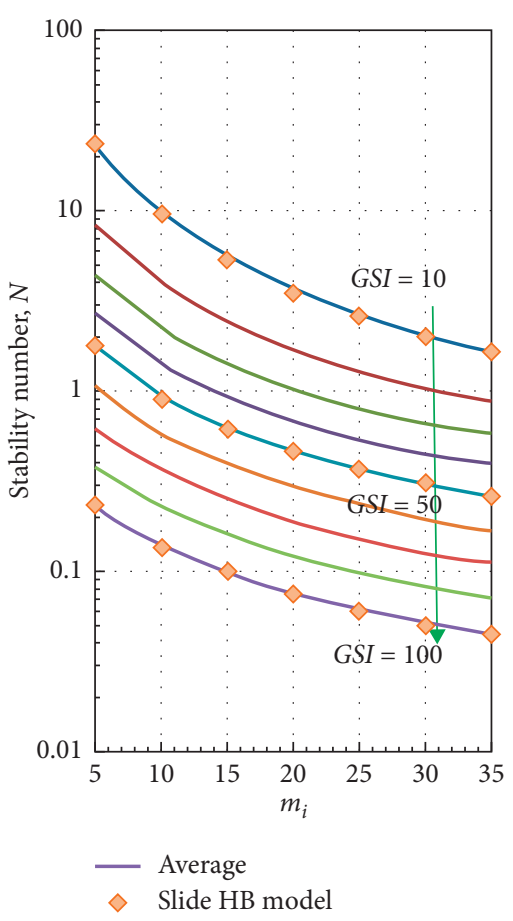

(a)

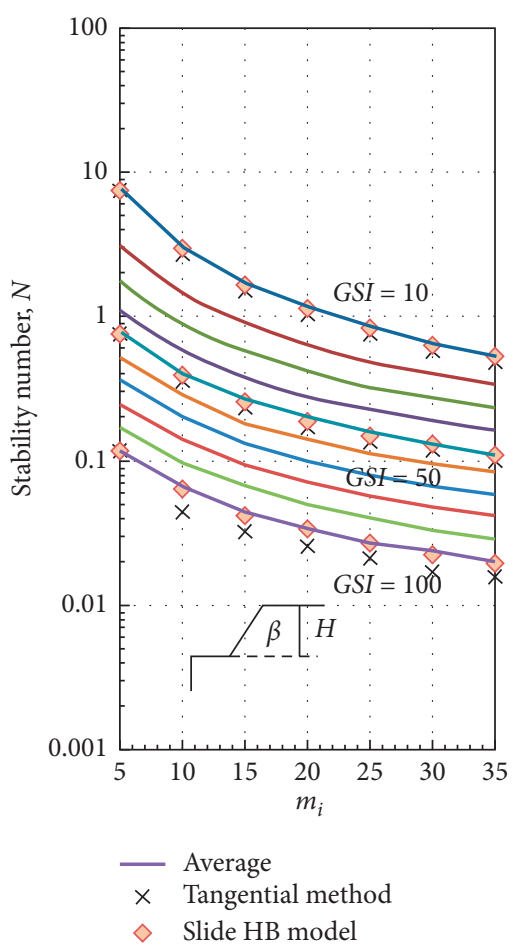

(b)

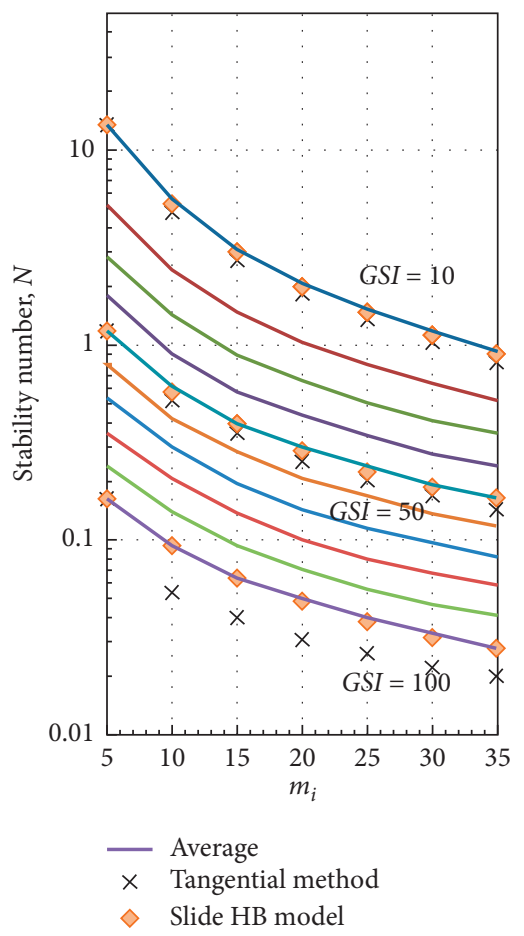

(c)

FIGURe 2: Seismic stability charts for rock slopes using the limit analysis method [22]. (a) $\beta=45^{\circ}, k_{h}=0.1$. (b) $\beta=45^{\circ}, k_{h}=0.2$. (c) $\beta=45^{\circ}, k_{h}=$ 0.3 .

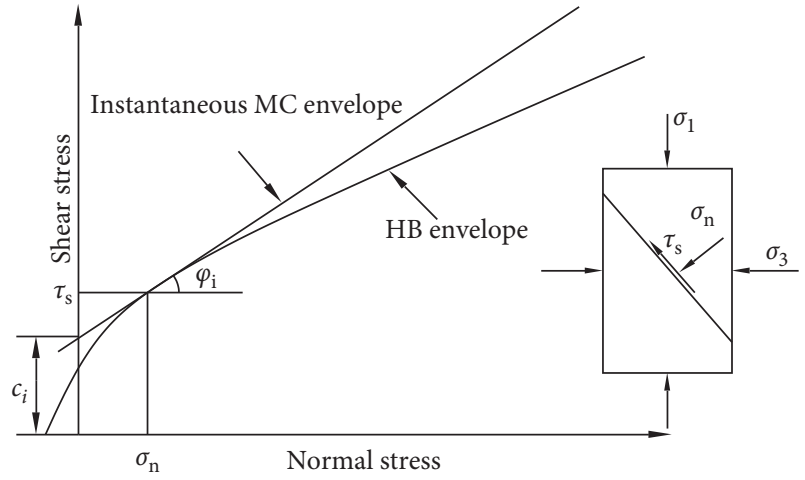

Figure 3: Relationship of instantaneous MC envelope and HB envelope in the normal and shear stress plane.

Based on the investigation of 20000 landslide histories caused by the Wenchuan Earthquake [40], the static analysis results reveal that most of the landslides have a slope angle exceeding $35^{\circ}$. Therefore, the slope angles are taken to be $30^{\circ}$, $45^{\circ}, 60^{\circ}$, and $75^{\circ}$ in our research. Slopes with the widely used values of the horizontal seismic acceleration coefficient of $0.1,0.2$, and 0.3 are analyzed.

3.4. Theoretical Relationship between the FOS and Related Parameters. For a rock slope with the given values of input parameters $s, \alpha, m_{\mathrm{b}}$, and $\sigma_{\mathrm{ci}},(8)$ and (9) can be used to calculate the minimum principal stress $\sigma_{3}$ and the shear stress $\tau_{s}$, respectively, and the simplified equations are simply described as

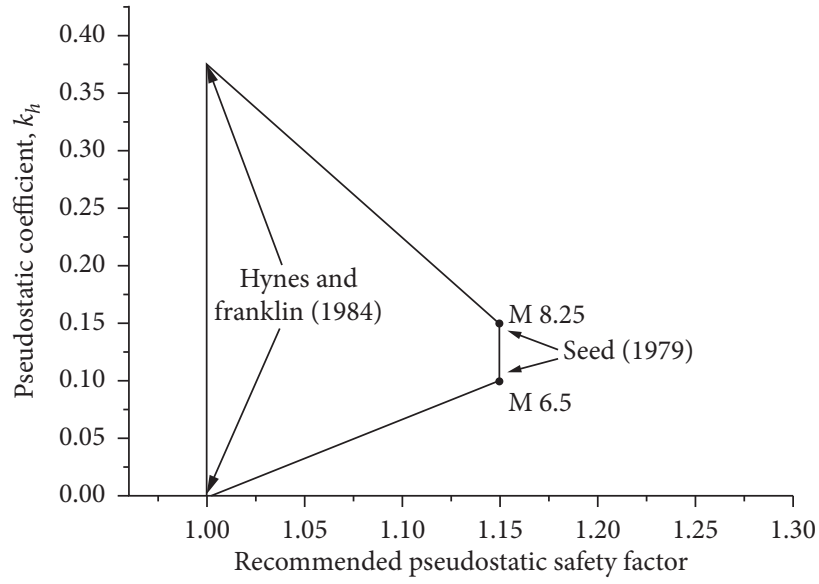

FIGURE 4: Design recommendations for pseudostatic analysis [39].

$$
\begin{aligned}
& \frac{\sigma_{3}}{\sigma_{c i}}=f_{1}\left(\frac{\sigma_{n}}{\sigma_{c i}}, m_{b}, s, \alpha\right), \\
& \frac{\tau_{s}}{\sigma_{c i}}=f_{2}\left(\frac{\sigma_{n}}{\sigma_{c i}}, m_{b}, s, \alpha\right) .
\end{aligned}
$$

When the dimensionless horizontal seismic coefficient $k_{h}$ is introduced to conduct the pseudostatic stability analysis for rock slopes under different horizontal seismic loading conditions, the FOS is defined as a function of the resisting shear force $T_{\mathrm{s}}$ divided by the mobilized shear force $T_{m}$, which 


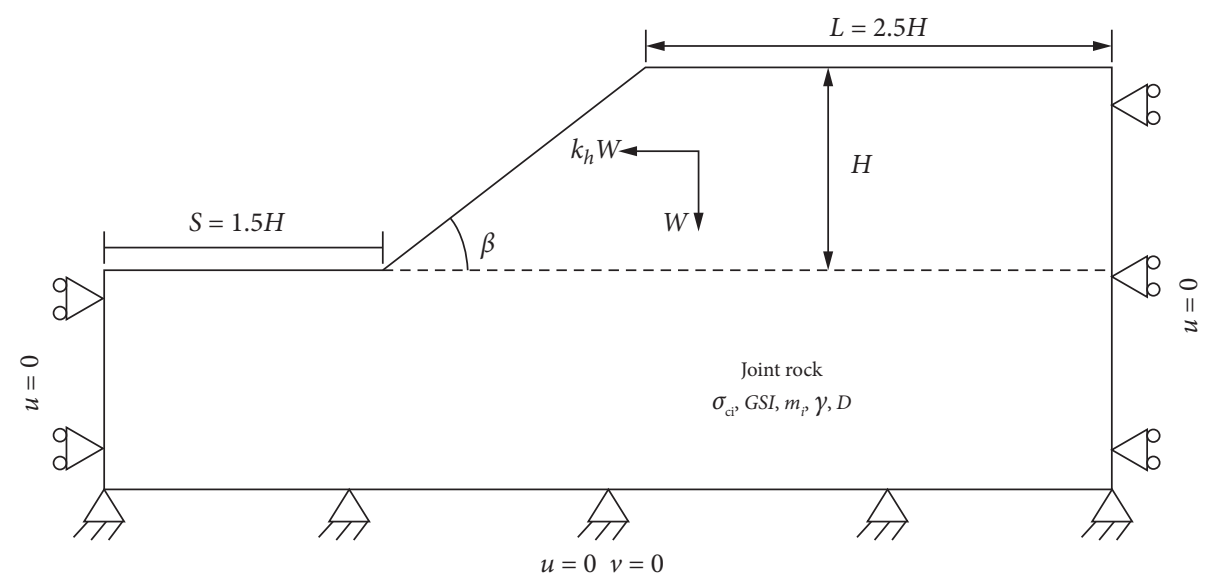

(a)

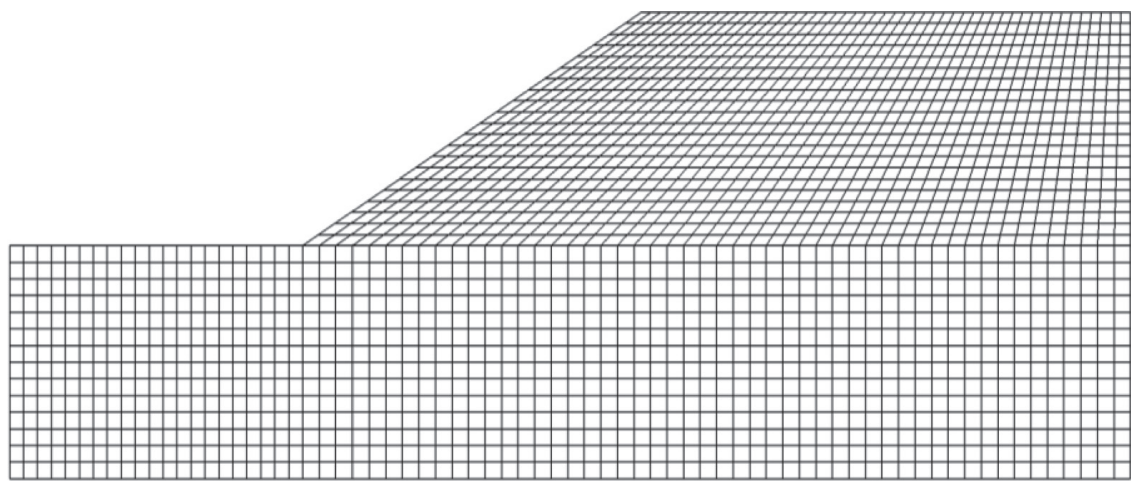

(b)

FIGURE 5: Sketch of definition for pseudostatic stability analysis of rock slope in this paper: (a) typical slope model and the boundary conditions; (b) mesh of the slope model.

can also be described in terms of the slice weight $\gamma H$ and the seismic inertia force $k_{h} \gamma H$, given by

$$
\begin{aligned}
& \left\{\begin{array}{l}
T_{s}=\gamma H \cos \beta-k_{h} \gamma H \sin \beta, \\
T_{m}=\gamma H \sin \beta+k_{h} \gamma H \cos \beta,
\end{array}\right. \\
& \text { FOS }=\frac{T_{s}}{T_{m}}=\frac{\tau_{s} d A}{\tau_{m} d A}=\frac{\tau_{s}}{\tau_{m}}=\frac{\tau_{s}}{\gamma H\left(\sin \beta+k_{h} \cos \beta\right)} \\
& =\frac{\tau_{s}}{\sigma_{c i}} * \frac{\sigma_{c i}}{\gamma H\left(\sin \beta+k_{h} \cos \beta\right)} \\
& =\frac{\sigma_{c i}}{\gamma H\left(\sin \beta+k_{h} \cos \beta\right)} f_{2}\left(\frac{\sigma_{n}}{\sigma_{c i}}, m_{b}, s, \alpha\right) \\
& =\frac{\sigma_{c i}}{\gamma H} f_{3}\left(\frac{\sigma_{n}}{\sigma_{c i}}, m_{b}, s, \alpha, k_{h}, \beta\right) \text {. }
\end{aligned}
$$

The normal stress $\sigma_{n}$ on the slip surface depends on the parameters of $\gamma H$ and $k_{h}$. Therefore, (15) can be described as follows:

$$
\mathrm{FOS}=f_{4}\left[\frac{\sigma_{c i}}{\gamma H} f_{3}\left(\frac{\gamma H}{\sigma_{c i}}, m_{b}, s, \alpha, k_{h}, \beta\right)\right] .
$$

The input parameters $m_{\mathrm{b}}, s$, and $\alpha$ in (16) can be determined from (2)-(4), respectively. Then, the final FOS can then be given by

$$
F O S=f_{5}\left(\frac{\sigma_{c i}}{\gamma H}, m_{b}, s, \alpha, k_{h}, \beta\right)=f_{6}\left(m_{i}, G S I, D, S R, k_{h}, \beta\right) .
$$

Equation (17) reveals that, for a rock slope with the given values of $m_{\mathrm{i}}$, GSI, $D, \beta$, and $k_{h}$, the FOS depends only on the nondimensional parameter of strength ratio $\mathrm{SR}\left(\mathrm{SR}=\sigma_{\mathrm{ci}} /\right.$ $€ H)$ despite the magnitude of $\sigma_{\mathrm{ci}}, \gamma$ and $H$. Therefore, the number of independent parameters for determining the FOS of a rock slope can be reduced to five (SR, $m_{\mathrm{i}}$, GSI, $D, \beta$, and $k_{h}$ ) under the condition of $D=0$, as shown in

$$
\mathrm{FOS}=f_{6}\left(\mathrm{SR}, \mathrm{GSI}, m_{i}, k_{h}, \beta\right) .
$$

To verify this theoretical relationship as shown in (18), Table 1 shows three slope cases with different values of $\gamma, \sigma_{c i}$, and $H$, which have the same values of SR, GSI, $m_{\mathrm{i}}, k_{h}$, and $\beta$. Then, the FOS values for these cases are calculated based on five different LEMs using Slide 6.0 and the nonlinear $\mathrm{HB}$ 
TABLE 1: Comparison of the FOS for a given slope with the same values of SR.

\begin{tabular}{|c|c|c|c|}
\hline Input parameters & Case 1 & Case 2 & Case 3 \\
\hline $\mathrm{B}\left({ }^{\circ}\right)$ & 45 & 45 & 45 \\
\hline GSI & 50 & 50 & 50 \\
\hline$m_{\mathrm{i}}$ & 15 & 15 & 15 \\
\hline$k_{h}$ & 0.1 & 0.1 & 0.1 \\
\hline$\sigma_{\mathrm{ci}}(\mathrm{MPa})$ & 27.6 & 50 & 100 \\
\hline$\gamma\left(\mathrm{kN} / \mathrm{m}^{3}\right)$ & 23 & 25 & 25 \\
\hline$H(\mathrm{~m})$ & 30 & 50 & 100 \\
\hline$S R\left(\sigma_{\mathrm{ci}} / \gamma H\right)$ & 40 & 40 & 40 \\
\hline Fellenius & 4.26 & 4.29 & 4.42 \\
\hline Simplified Bishop & 4.38 & 4.41 & 4.45 \\
\hline Simplified Janbu & 4.39 & 4.43 & 4.46 \\
\hline Spencer & 4.42 & 4.45 & 4.48 \\
\hline \multicolumn{4}{|l|}{ FOS } \\
\hline Morgenstern Price & 4.49 & 4.55 & 4.52 \\
\hline HB strength reduction technique (present study) & 4.47 & 4.52 & 4.50 \\
\hline
\end{tabular}

strength reduction method by the software ABAQUS 6.10, and the results are listed in Table 1. Values of the FOS for all the three cases are exactly the same. For further study, three additional groups that have the same values of SR, $k_{h}$, and $\beta$ over a range of GSI and $m_{\mathrm{i}}$ were analyzed, and the FOS results are given in Table 2 . The FOS depends only on the magnitude of SR for slopes with the same values of GSI, $m_{\mathrm{i}}$, $\beta$, and $k_{h}$. Based on this observation, stability charts for rock slopes can easily be developed under different seismic loading conditions.

\section{Results and Analysis}

4.1. Stability Charts for Rock Slopes with $\beta=45^{\circ}$ under Static and Pseudostatic Conditions. Using the previously expressed parameters for stability analysis in previous section, first, a set of charts for rock slope stability with a specific slope angle of $\beta=45^{\circ}$ under static conditions $\left(k_{h}=0\right)$ is developed in this section, as shown in Figure 6. Figure 6 reveals that the FOS clearly increases with the increase of SR and GSI. For instance, as illustrated in Figure 6(a), when $\mathrm{SR}=1.0$, increasing the geological strength index from GSI $=10$ to 100 can increase the FOS by more than 6 times. The values of SR also have a remarkable impact on rock slope stability, especially under the conditions of high GSI values, but, for low values of GSI $\leq 60$, the FOS can be seen to increase slightly with the increase of SR. For instance, in Figure 6(a), when GSI = 100, the value of FOS is equal to 4.94 for $\mathrm{SR}=2.0$ and increases to 17.88 for $\mathrm{SR}=10$. When $\mathrm{GSI}=10$, the FOS is 0.58 for $\mathrm{SR}=2$ and increases to 0.95 for $S R=10$. The charts presented in Figure 6 provide a good benchmark and foundation for comparison in subsequent parts.

Figure 7 illustrates the relationship between the FOS and $m_{\mathrm{i}}$, GSI, and SR for a slope with $k_{h}=0.1,0.2$, and 0.3 and $\beta=45^{\circ}$. The FOS increases slightly with the increase of SR when the GSI values are at low levels $(\mathrm{GSI} \leq 60)$, and the maximum value of $m_{\mathrm{i}}=35$ and the minimum value of $m_{\mathrm{i}}=5$ yield a narrow range of FOS values. Nevertheless, the FOS can be seen to increase dramatically as SR increases when GSI $>$ 60. In addition, as Figure 7 shows, the FOS for
TABLE 2: Comparison of the FOS for a given rock slope with various HB parameters.

\begin{tabular}{cccccc}
\hline \multicolumn{2}{c}{ Input parameters } & \multicolumn{3}{c}{ FOS } \\
& GSI & $m_{\mathrm{i}}$ & Group 1 & Group 2 & Group 3 \\
\hline & 10 & 5 & 1.2 & 1.2 & 1.2 \\
& 10 & 15 & 1.71 & 1.71 & 1.71 \\
& 10 & 25 & 2.01 & 2.01 & 2.03 \\
& 10 & 35 & 2.23 & 2.23 & 2.24 \\
$\beta=45^{\circ}$ & 50 & 5 & 4.5 & 4.51 & 4.52 \\
$k_{h}=0.1$ & 50 & 15 & 4.52 & 4.53 & 4.53 \\
$\mathrm{SR}=40$ & 50 & 25 & 4.7 & 4.69 & 4.7 \\
& 50 & 35 & 4.89 & 4.88 & 4.89 \\
& 100 & 5 & 46.2 & 46.21 & 4.19 \\
& 100 & 15 & 35.25 & 35.26 & 35.25 \\
& 100 & 25 & 30.81 & 30.79 & 30.81 \\
& 100 & 35 & 27 & 27.02 & 26.99 \\
\hline
\end{tabular}

different values of $m_{\mathrm{i}}$ meets at one point at high GSI values, so, for the small SR values (smaller than the intersection points), the FOS increases with the increase in $m_{\mathrm{i}}$, but while the SR values exceed the intersection points, the FOS decreases when $m_{\mathrm{i}}$ increases. As expected, when the charts in Figure 7 are compared with the charts in Figure 6, we conclude that $k_{h}$ has a remarkable influence on the rock slope stability. For instance, when $m_{\mathrm{i}}=15, \mathrm{GSI}=50$, and $\mathrm{SR}=10$ (Figure 6(c)), the FOS values decrease from 3.05 to $2.55,2.17$, and 1.87 with $k_{h}$ increasing from 0 to 0.3 .

\subsection{Charts for the Seismic Weighting Factor $f_{k h}$ and the Slope} Angle Weighting Factor $f_{\beta}$. In previous section, both the slope angle $(\beta)$ and the horizontal seismic acceleration coefficient $\left(k_{h}\right)$ have significant effects on rock slope stability. The main purpose of this section is to produce the charts for the seismic weighting factor $\left(f_{k h}\right)$ and the slope angle weighting factor $\left(f_{\beta}\right)$ for use in rock slope stability analysis.

4.2.1. Seismic Weighting Factor $f_{k h}$. The seismic weighting factor $f_{k h}$ is defined as the ratio of the FOS under the seismic condition to the FOS under static conditions and adopted to examine the influence of $k_{h}$ on stability of the rock slope. The 

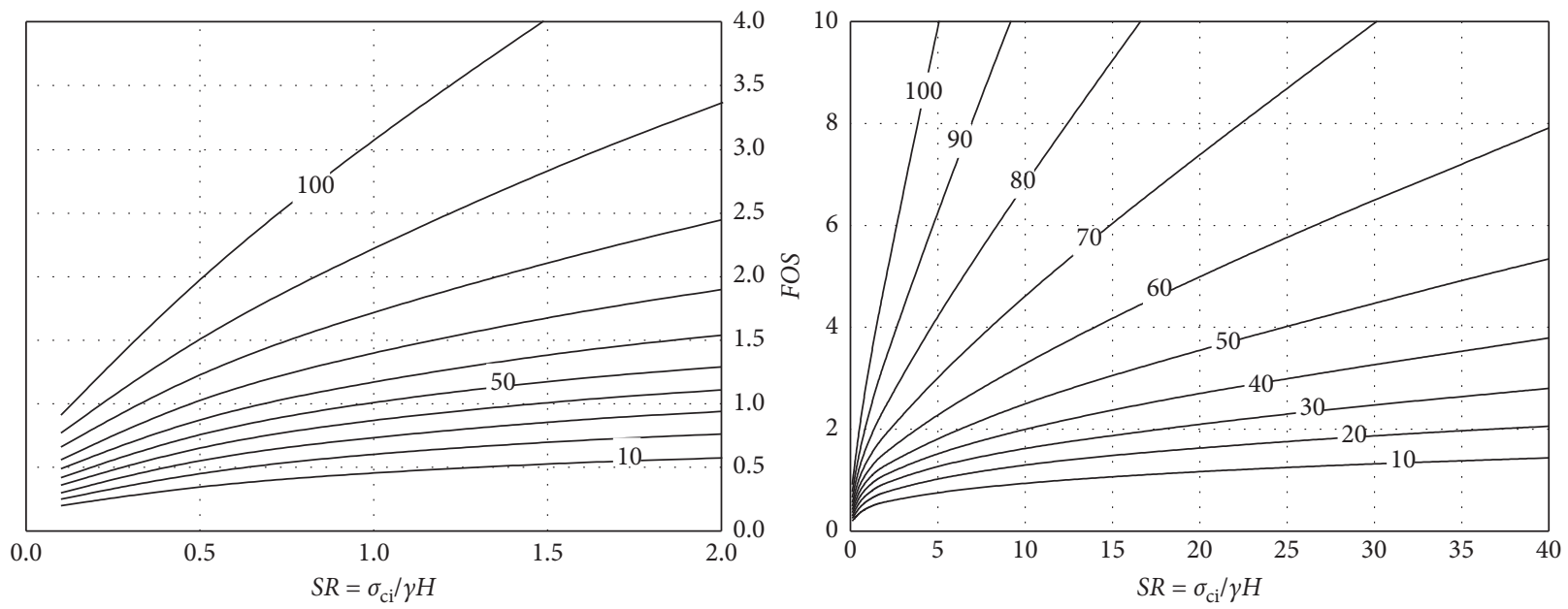

(a)
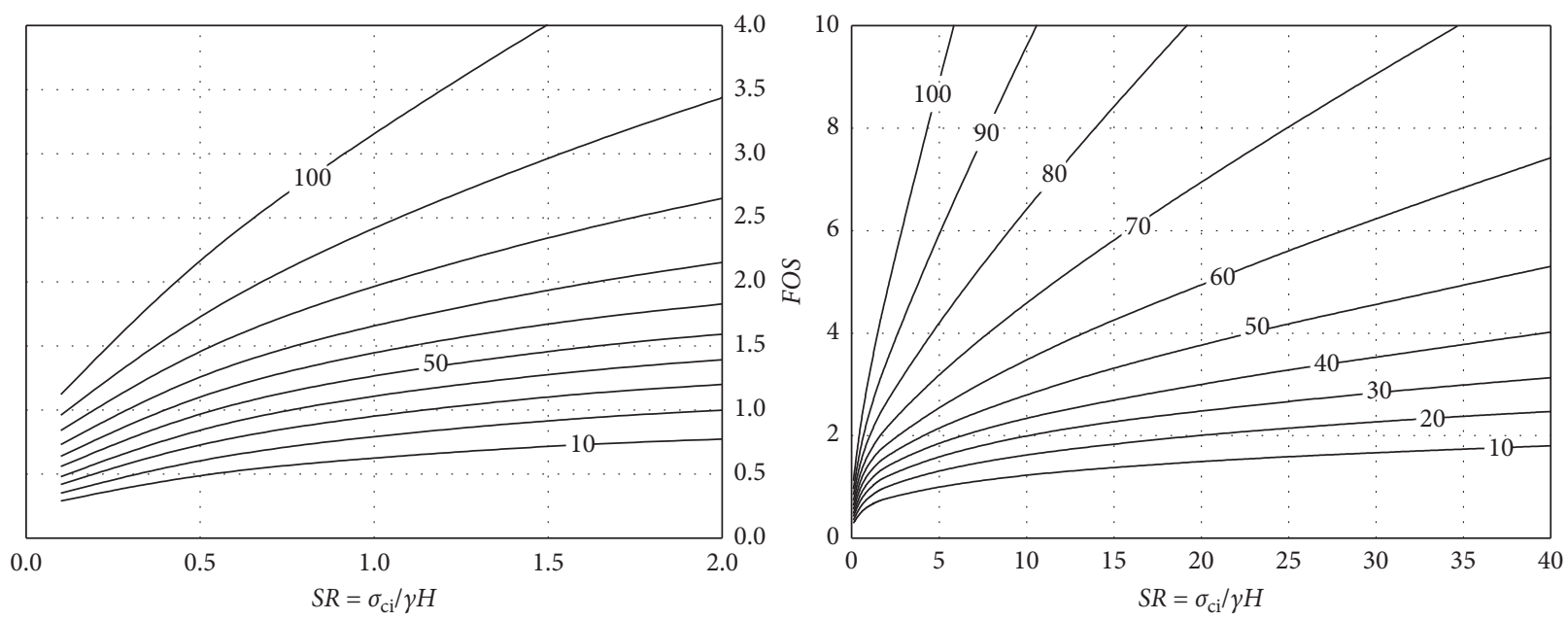

(b)
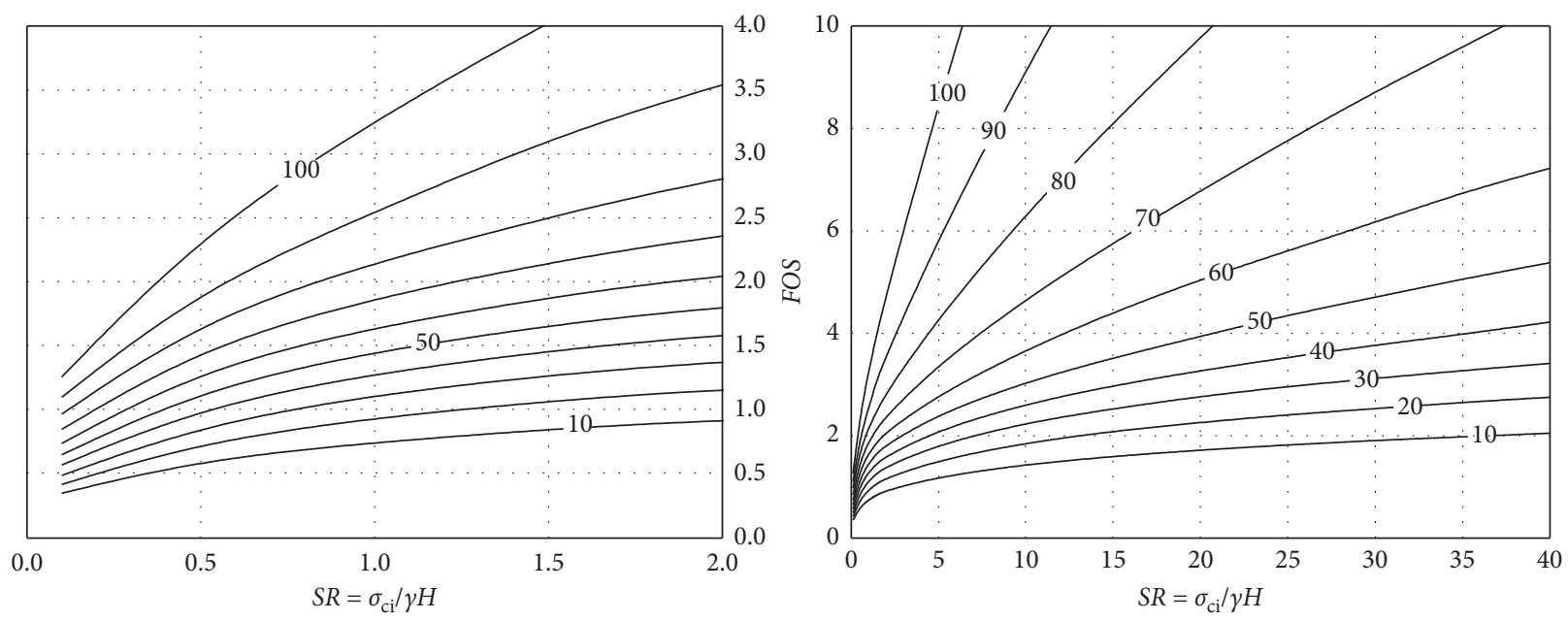

(c)

Figure 6: Continued. 

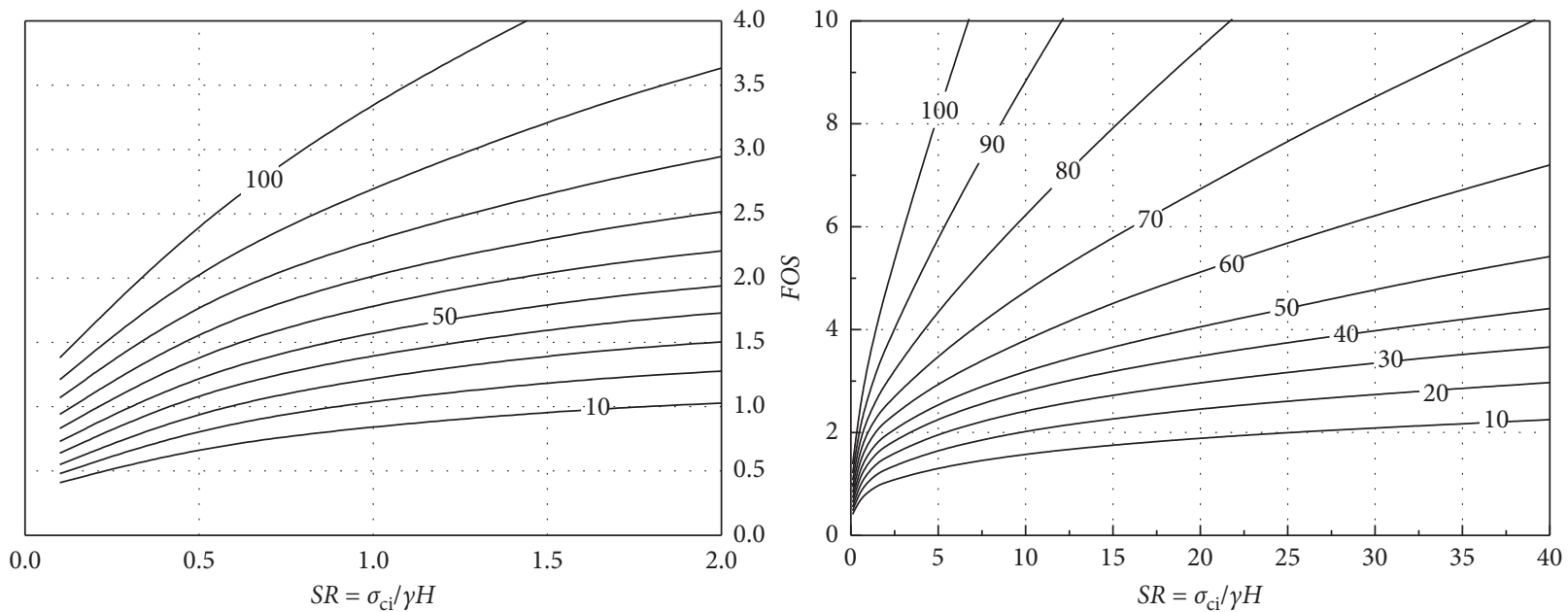

(d)
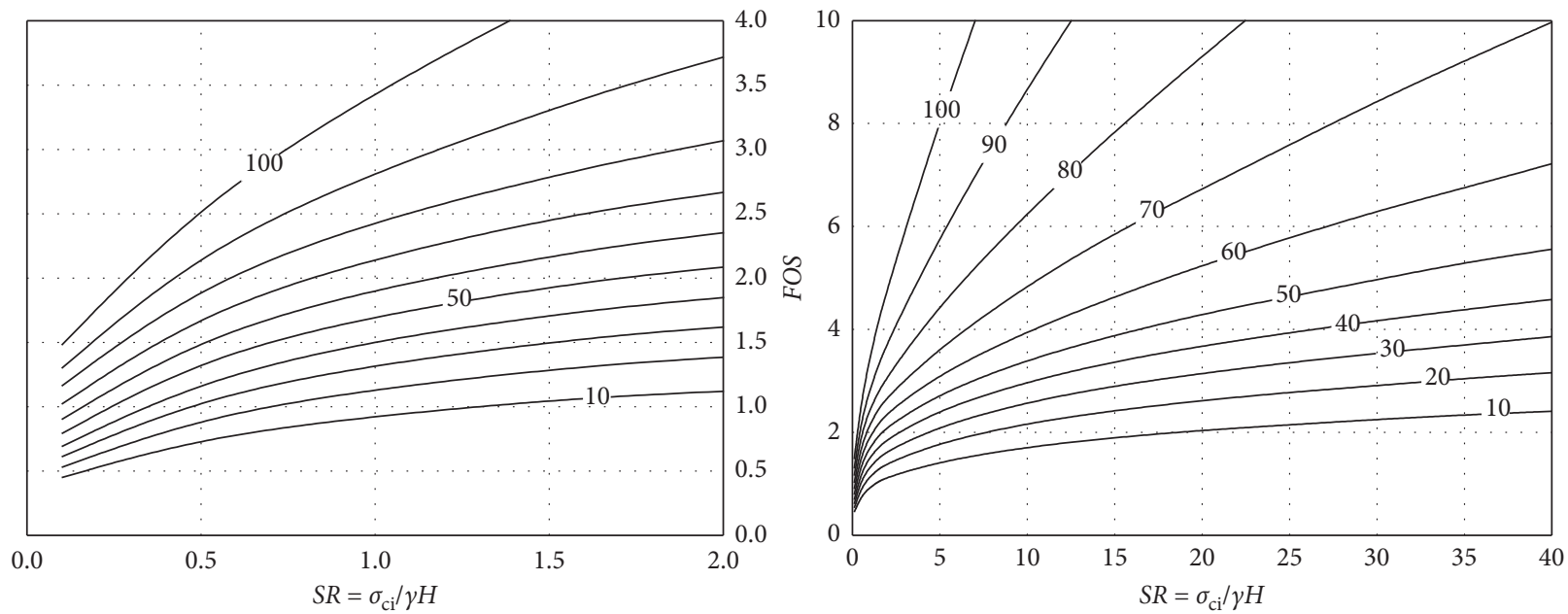

(e)
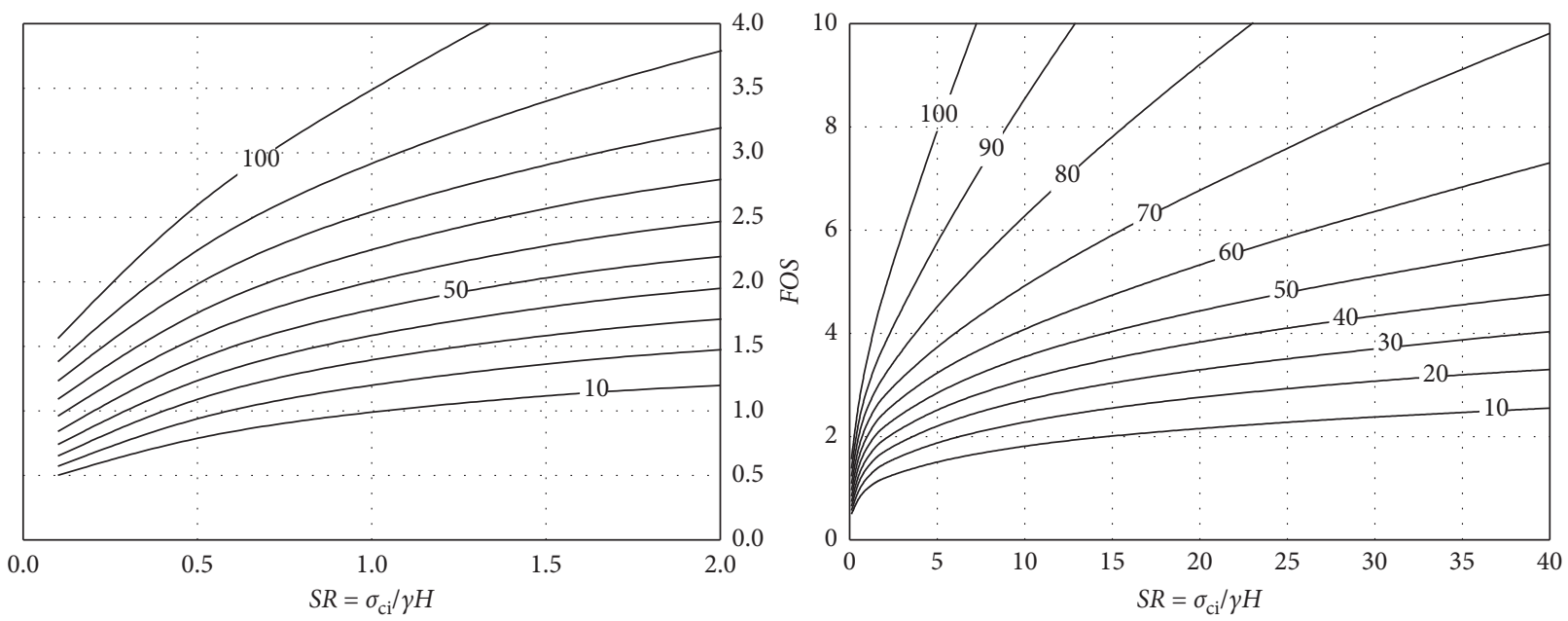

(f)

Figure 6: Continued. 

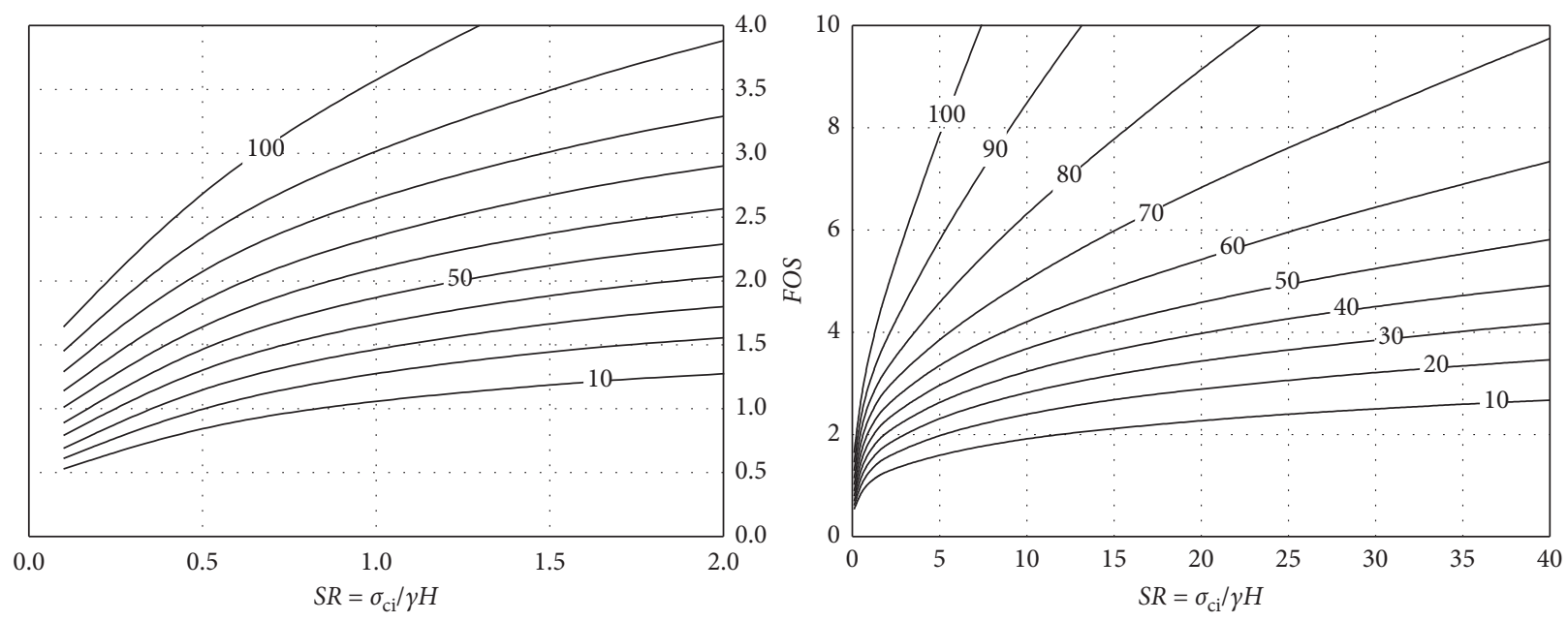

$(\mathrm{g})$

FIGURE 6: Stability charts for rock slopes with $\beta=45^{\circ}$ under static conditions $k_{h}=0$ : (a) $m_{i}=5$; (b) $m_{i}=10$; (c) $m_{i}=15$; (d) $m_{i}=20$; (e) $m_{i}=25$; (f) $m_{i}=30 ;(\mathrm{g}) m_{i}=35$.

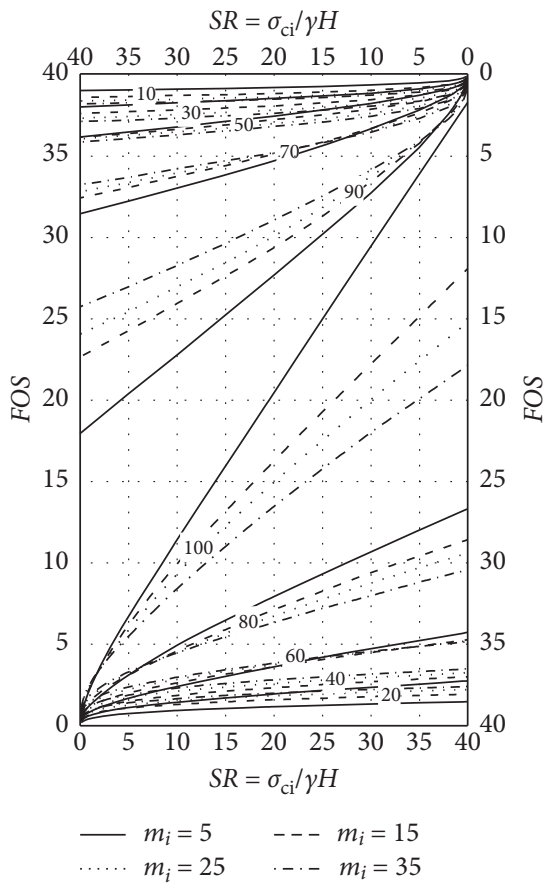

(a)

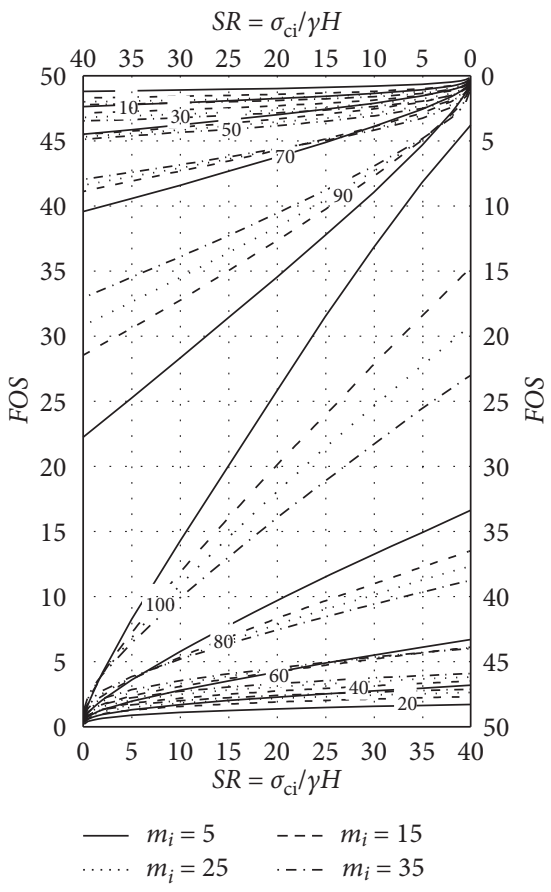

(b)

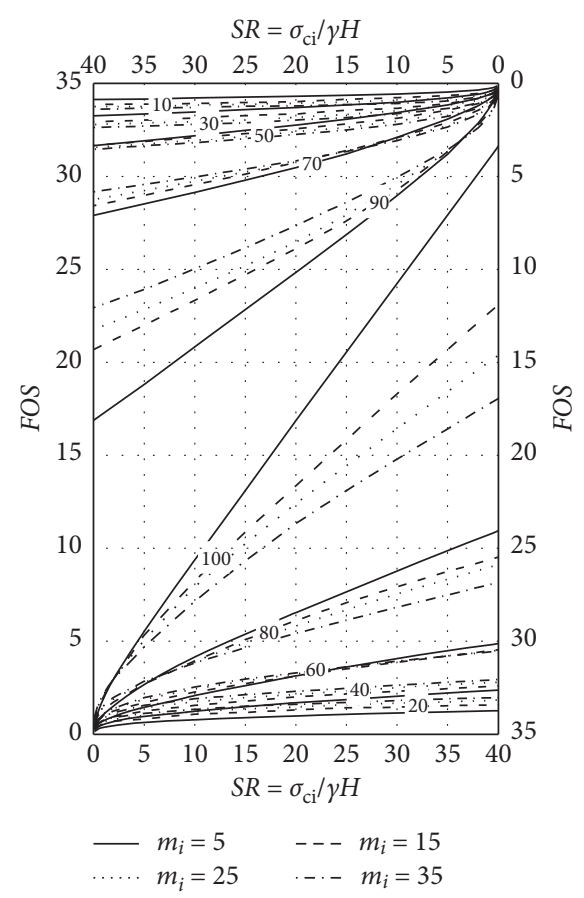

(c)

FIGURE 7: Stability charts for rock slopes with $\beta=45^{\circ}$ under pseudostatic condition: (a) $k_{h}=0.1$; (b) $k_{h}=0.2$; (c) $k_{h}=0.3$. Note. In this figure, the biaxial coordinate is adopted to differentiate the trends of curves with different GSI values in one chart.

horizontal seismic acceleration coefficient $k_{h}$ is assigned values ranging from 0.1 to 0.3 while the values of $\mathrm{SR}, m_{\mathrm{i}}$, and GSI are the same as slope models with $\beta=45^{\circ}$. Then, the FOS for the slope is calculated, and the factor of $f_{k h}$ is obtained. Figure 8 gives the statistical data analysis results of the seismic weighting factor for slopes with $\beta=30^{\circ}, 45^{\circ}, 60^{\circ}$, and $75^{\circ}$. For a slope with $\beta=30^{\circ}$ and $k_{h}=0.1$ (Figure $8(\mathrm{a})$ ), the minimum and maximum values of the seismic weighting factors are 0.745 and 0.825 , respectively, the average value is
0.802 , and a majority of the values of $f_{k h}$ are located around the average values. In addition, as expected, the seismic weighting factor $f_{k h}$ obviously decreases as $k_{h}$ increases. For example, the average seismic weighting factor decreases from 0.802 to 0.544 when $k_{h}$ increases from 0.1 to 0.3 . The same regularity of statistical distribution can also be found for slopes with $\beta=45^{\circ}, 60^{\circ}$, and $75^{\circ}$, as illustrated in Figures 8 (b)-8(d). Finally, the curve fitting methods are used to obtain the exponential functions with a high fitting degree 


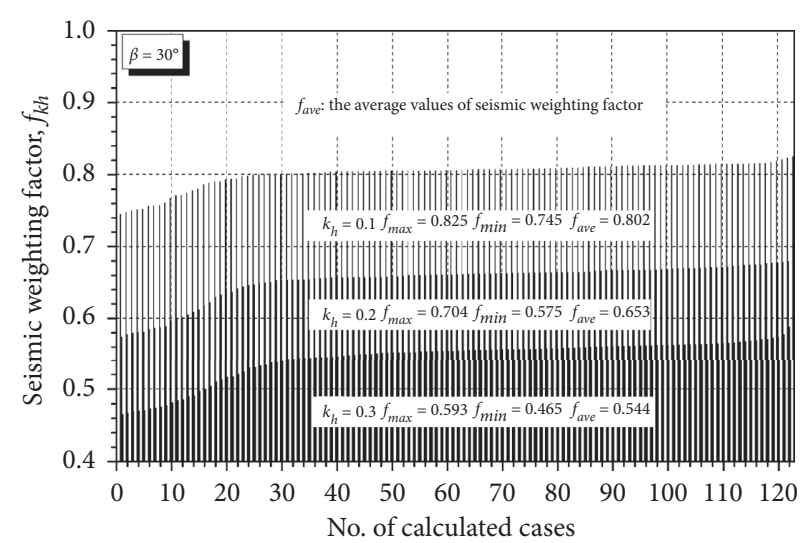

(a)

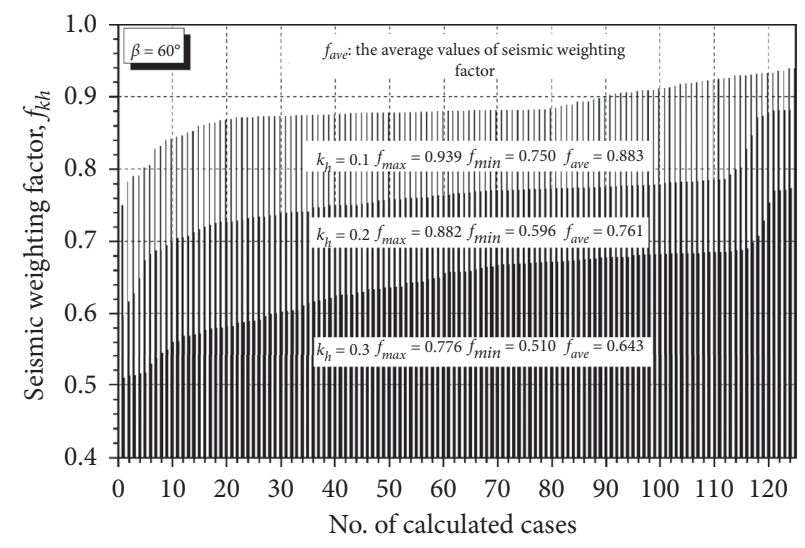

(c)

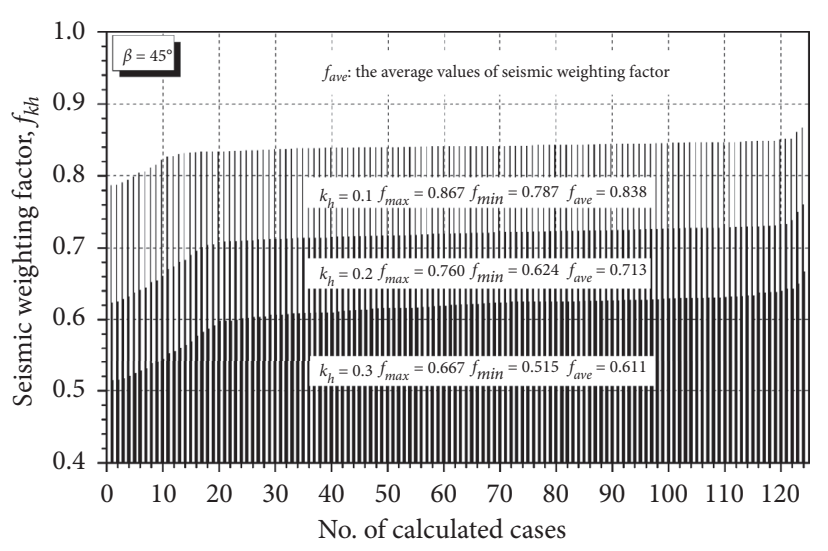

(b)

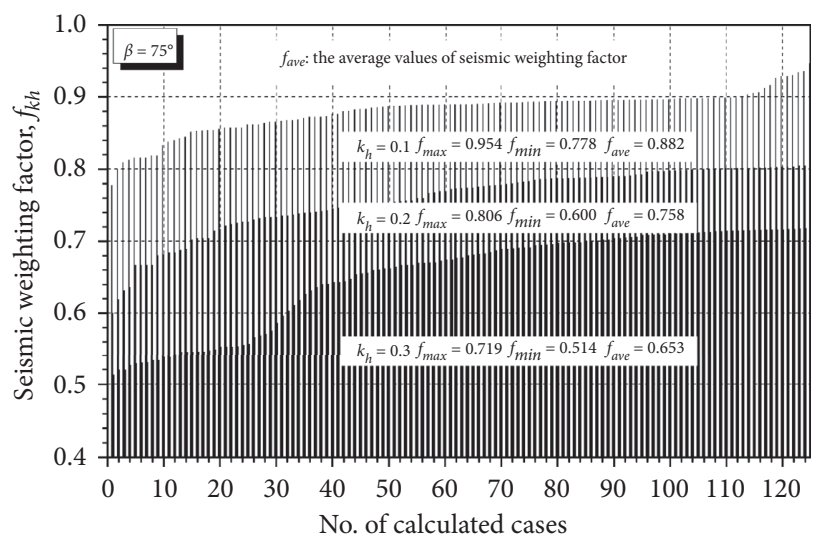

(d)

FIgURE 8: The seismic weighting factors for rock slopes with (a) $\beta=30^{\circ}$, (b) $\beta=45^{\circ}$, (c) $\beta=60^{\circ}$, and (d) $\beta=75^{\circ}$.

for slopes with $\beta=30^{\circ}, 45^{\circ}, 60^{\circ}$, and $75^{\circ}$, and the results are shown in Table 3.

For further study, Figure 9 presents the relationship between the seismic weighting factor and the horizontal seismic acceleration coefficient. The maximum value of $\beta=75^{\circ}$ and the minimum value of $\beta=30^{\circ}$ obviously yield a narrow range of values of the seismic weighting factor $f_{k h}$, which means that the effect of the slope angle on the seismic weighting factor is small. Therefore, the average values of $f_{k h}$ are used to establish the simplified fitting equation, and the result is given as follows:

$$
f_{k h}=1.006\left(k_{h}\right)^{2}-1.594\left(k_{h}\right)+1.0 .
$$

4.2.2. Slope Angle Weighting Factor $f_{\beta}$. The slope angle weighting factor $f_{\beta}$, which is defined as the ratio of the FOS under other various slope angles to the FOS under $\beta=45^{\circ}$, is adopted to describe the effect of slope angles on the rock slope stability. The first procedure for determining the weighting factor of $f_{\beta}$ is to calculate the FOS under slope angles ranging from $30^{\circ}$ to $75^{\circ}$ with the same values of $m_{\mathrm{i}}$, GSI, SR, and $k_{h}$. After hundreds of runs to conduct the stability analysis for various slopes with a wide range of geometries and rock mass parameters, the statistical results of the slope angle weighting factor under the seismic
TABLE 3: Regression equations for the seismic weighting factors.

\begin{tabular}{lcc}
\hline Slope angle, $\beta$ & Regression equations, $f_{k h}$ & Fitting degree, $R^{2}$ \\
\hline $30^{\circ}$ & $f_{k h}=0.99 e^{-2.0 k h}$ & 0.998 \\
$45^{\circ}$ & $f_{k h}=0.99 e^{-1.6 k h}$ & 0.999 \\
$60^{\circ}$ & $f_{k h}=1.01 e^{-1.47 k h}$ & 0.996 \\
$75^{\circ}$ & $f_{k h}=1.01 e^{-1.47 k h}$ & 0.996 \\
\hline
\end{tabular}

conditions of $k_{h}=0,0.1,0.2$, and 0.3 are shown in Figure 10. The results reveal that when $\beta=30^{\circ}$ and $k_{h}=0$ (Figure 10(a)), the minimum and maximum values of the slope angle weighting factor are 1.413 and 1.106 , respectively, and the average value is 1.330 . In addition, most of the slope angle weighting factors are distributed within the scope of the average values. Furthermore, it is observed that $f_{\beta}$ decreases as $\beta$ increases. For example, the average value of $f_{\beta}$ decreases from 1.274 to 0.629 when $\beta$ increases from $30^{\circ}$ to $75^{\circ}$. The same statistical distribution regularity is also found for slopes with $k_{h}=0.1,0.2$, and 0.3 in Figures $10(\mathrm{~b})-10$ (d).

Figure 11 shows the relationship between the slope angle weighting factor and the slope angle. The minimum value of $k_{h}=0$ and maximum value of $k_{h}=0.3$ are easily observed to generate a narrow scope of the slope angle weighting factor $f_{\beta}$, which means that $k_{h}$ has relatively little effect on $f_{k h}$. Therefore, the average values of the seismic weighting factor 


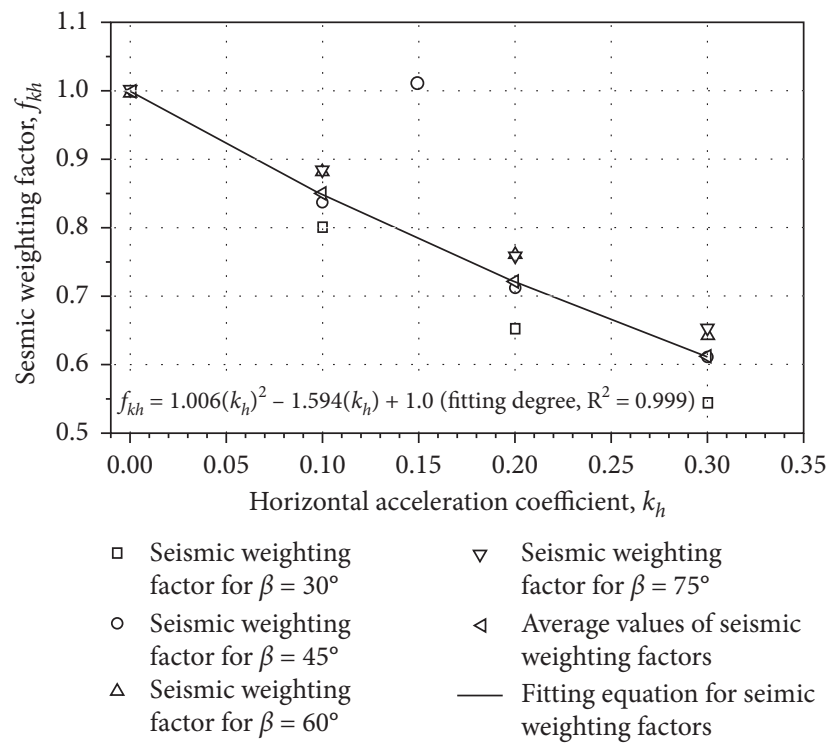

FIgURE 9: The chart for seismic weighting factor.

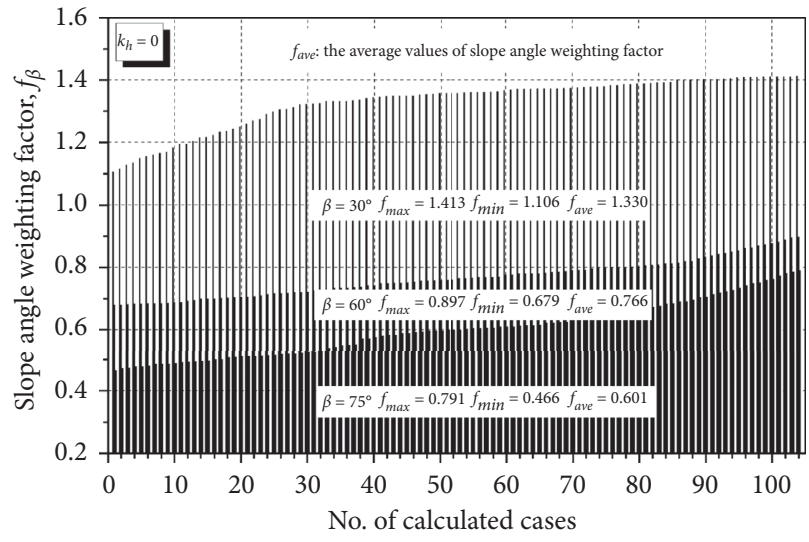

(a)

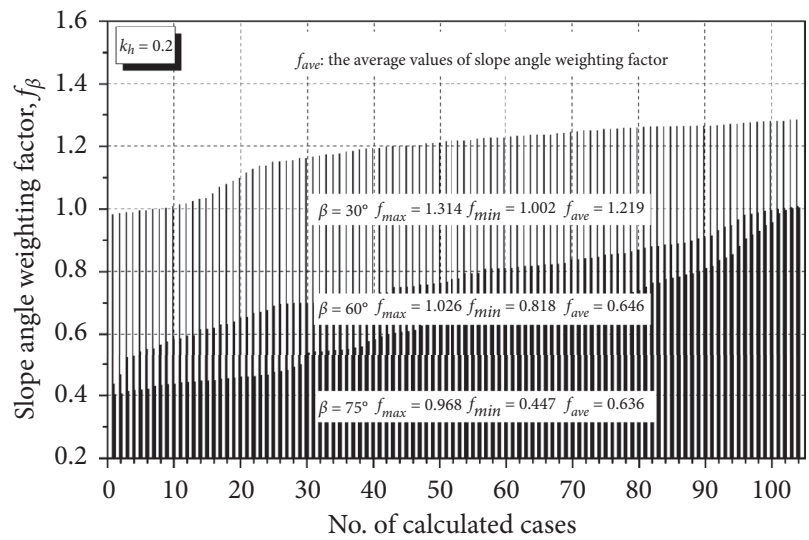

(c)

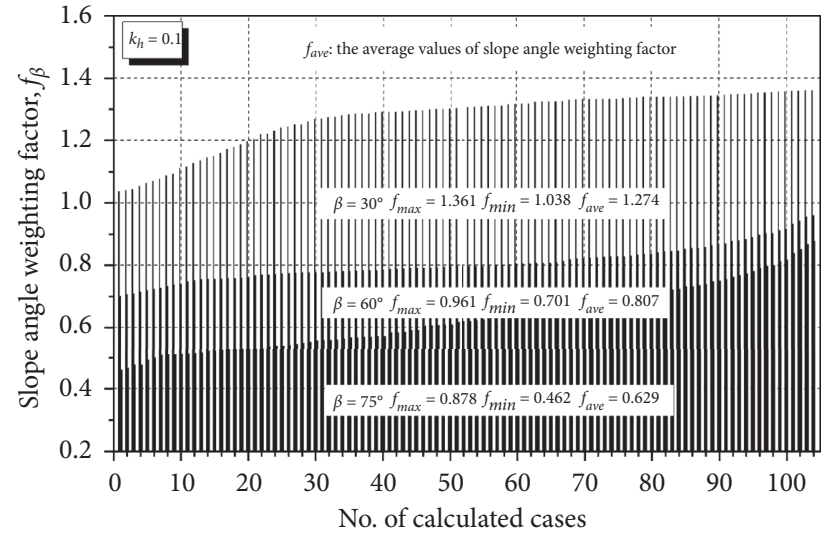

(b)

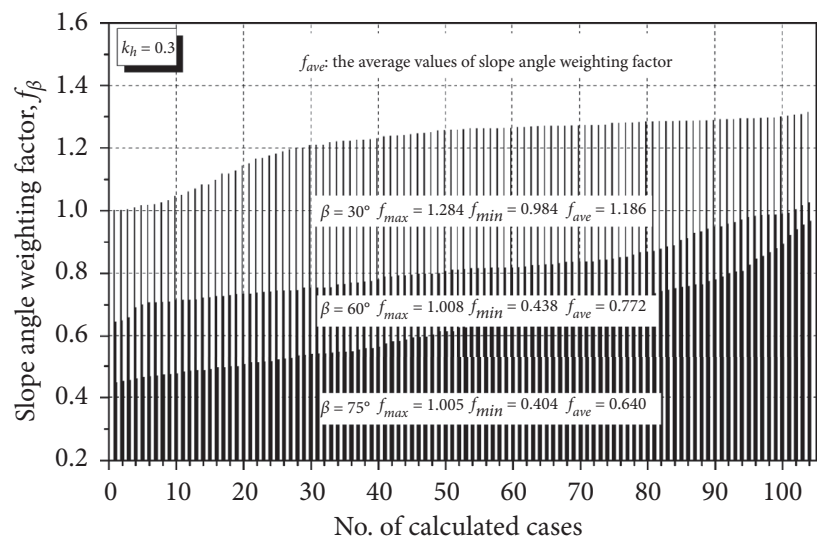

(d)

FIgURE 10: The slope angle weighting factors: (a) $k_{h}=0$; (b) $k_{h}=0.1$; (c) $k_{h}=0.2$; (d) $k_{h}=0.3$. 


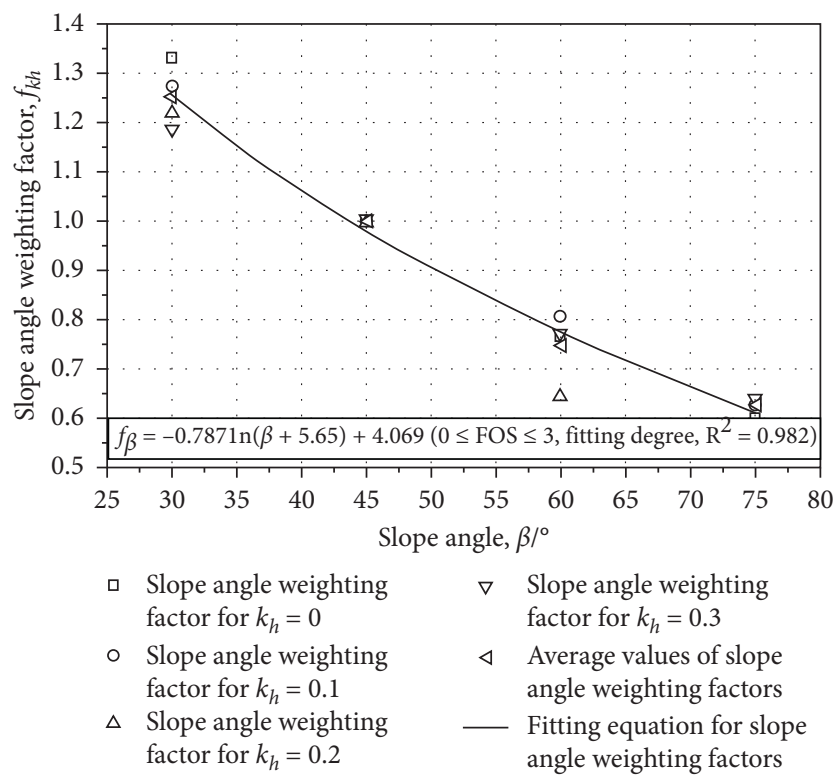

FIgURE 11: The chart for the slope angle weighting factor.

are used to establish the simplified fitting equation, which is given as follows:

$$
f_{\beta}=-0.787 \ln (\beta+5.65)+4.069 .
$$

4.3. Use and Validation of the Proposed Seismic Stability Charts. The proposed seismic stability charts can easily be applied to determine the FOS of a given rock slope. First, when the values of GSI, $m_{\mathrm{i}}$, and SR are given, the FOS for $\beta=45^{\circ}$ and $k_{h}=0$ can be obtained based on the charts in Figure 5. Second, the seismic weighting factor $f_{k h}$ for any given value of $k_{h}$ can be determined from Figure 8 or (19). Then, for a given value of slope angle $\beta$, Figure 10 or (20) can be used to obtain the slope angle weighting factor $f_{\beta}$. Finally, the FOS can be obtained as follows:

$$
F=f_{\beta} \times f_{k h} \times F O S_{\beta=45^{\circ}} .
$$

The following three examples with different slope geometries and rock mass parameters are adopted to elaborate the use of the proposed charts. Example 1: a small slope consists of highly fractured rock masses with the following input parameters: $\sigma_{\mathrm{ci}}=2.7 \mathrm{MPa}, m_{\mathrm{i}}=5, \mathrm{GSI}=10, \beta=30^{\circ}$, $H=5 \mathrm{~m}, \gamma=27 \mathrm{kN} / \mathrm{m}^{3}$, and $k_{h}=0.1$. Example 2: a medium slope consists of good quality rock masses with the following input parameters: $\sigma_{\mathrm{ci}}=0.625 \mathrm{MPa}, m_{\mathrm{i}}=15, \mathrm{GSI}=80, \beta=75^{\circ}$, $H=25 \mathrm{~m}, \gamma=25 \mathrm{kN} / \mathrm{m}^{3}$, and $k_{h}=0.2$. Example 3: a large open pit slope consists of blocky rock masses with the following input parameters: $\sigma_{\mathrm{ci}}=46 \mathrm{MPa}, m_{\mathrm{i}}=35, \mathrm{GSI}=50$, $\beta=60^{\circ}, H=250 \mathrm{~m}, \gamma=23 \mathrm{kN} / \mathrm{m}^{3}$, and $k_{h}=0.3$. According to the procedures for application of the charts presented, Table 4 shows the calculation results of the three examples. The results of FOS obtained from the charts presented show good agreement with the results obtained from the software of Slide 6.0, which validates the feasibility and reliability of the proposed seismic stability charts.
TABLE 4: Three slope examples analyzed using the proposed seismic stability charts.

\begin{tabular}{lccc}
\hline Input parameters & Example 1 & Example 2 & Example 3 \\
\hline$\beta\left(^{\circ}\right)$ & 30 & 75 & 60 \\
$\mathrm{GSI}$ & 10 & 80 & 50 \\
$m_{\mathrm{i}}$ & 5 & 15 & 35 \\
$k_{h}$ & 0.1 & 0.2 & 0.3 \\
$\sigma_{\mathrm{ci}}(\mathrm{MPa})$ & 2.7 & 0.625 & 46 \\
$\gamma\left(\mathrm{kN} / \mathrm{m}^{3}\right)$ & 27 & 25 & 23 \\
$H(\mathrm{~m})$ & 5 & 25 & 250 \\
$\mathrm{SR}\left(\sigma_{\mathrm{ci}} / \gamma H\right)$ & 20 & 0.625 & 8 \\
$\quad$ FOS & $\beta=45^{\circ}$ & 3.085 & 3.434 \\
\hline Calculated data & 1.170 & & \\
$\quad f_{\beta}$ & 1.256 & 0.614 & 0.776 \\
$\quad f_{k h}$ & 0.851 & 0.721 & 0.612 \\
$\quad$ Proposed charts & 1.251 & 1.366 & 1.631 \\
\hline FOS & & & \\
$\quad$ Slide 6.0 software & 1.320 & 1.381 & 1.642 \\
\hline
\end{tabular}

\section{Application of the Seismic Stability Charts to Case Studies}

5.1. Case 1: A Rock Slope in Zipingpu Reservoir. The cases analyzed in this research are adopted from the studies of Jiang et al. [28]. The rock slope analyzed is located $1.2 \mathrm{~km}$ away in the northern bank of the Zipingpu Reservoir of Sichuan, China. According to the field investigations of Jiang et al. [28], the lithology of the rock mass within this slope is mainly dolomite. The slope has a height of $100 \mathrm{~m}$ with a slope angle of $50^{\circ}$. The unit weight of the dolomite rock mass is $28 \mathrm{kN} / \mathrm{m}^{3}$; the uniaxial compressive strength of the intact rock mass $\sigma_{\mathrm{ci}}$ is $100 \mathrm{MPa}$, and the $\mathrm{HB}$ parameter $m_{\mathrm{i}}$ is 10 . Based on the detailed mapping work, there are three dominant joint sets (J1, J2, and J3) and one damage zone within the slope. The discontinuities are slightly weathered 
planar surfaces, and the persistence ranges from 0.2 to $3.0 \mathrm{~m}$ with the apertures $<1.0 \mathrm{~mm}$ and soft clay in it. The measuring results show that the discontinuities are closely spaced with $\lambda$ ranging from 10 to 15 .

5.2. Case 2: Huanggang Landslide. The Huanggang landslide, a rock slope failure that occurred in the Wenchuan earthquake in May 2008 in northwest Chengdu, China, consists of the failure of $1.5 \mathrm{Mm}^{3}$ of gray sandstone material with shallow loose surface deposits. The height of the Huanggang landslide is $140 \mathrm{~m}$, and the original slope angle is $53^{\circ}$. The unit weight of the dolomite rock mass is $24 \mathrm{kN} / \mathrm{m}^{3}$. The $\mathrm{HB}$ parameter $m_{\mathrm{i}}$ is 18 , and the uniaxial compressive strength of the intact rock mass is $50 \mathrm{MPa}$. Five dominant discontinuity sets were recognized during field investigation along the failure plane and the side-scarps. The discontinuity persistence ranges from 0.2 to $8.0 \mathrm{~m}$ with apertures $<1.0 \mathrm{~mm}$ and soft clay filling. The linear density of the discontinuity $\lambda$ ranges from 17 to 28 .

According to the calculation of Jiang et al. [28], the values of GSI range from 43 to 72 for Case 1 and range from 17 to 45 for Case 2. The lower GSI values, e.g., GSI = 43 for Case 1 and GSI = 17 for Case 2, are used in these case studies. Table 5 gives the parameters for analysis of the two cases using the proposed seismic stability charts. The detailed process of the chart-based analysis for the two cases is described as follows.

For Case 1, first, using the values of $m_{\mathrm{i}}=10, \mathrm{GSI}=40$, and $\mathrm{SR}=\sigma_{\mathrm{ci}} / \gamma H=100000 /(28 \times 100) \approx 35$, Figure $6(\mathrm{~b})$ reads $\mathrm{FOS}_{\beta=45^{\circ}}=3.780$. Second, based on $\beta=50^{\circ}$ and $k_{h}=0.2$, Figure 9 or (19) gives the value of $f_{k h}$ and Figure 11 or (20) provides the value of $f_{\beta}$, and the results are $f_{k h}=0.721$ and $f_{\beta}=0.906$. Finally, the FOS for Case 1 is calculated in (21), and the result is 2.469 .

For Case 2, to begin with, Figures 6(c) and 6(d) are used to determine the range of $\mathrm{FOS}_{\beta=45^{\circ}}$ values for $m_{\mathrm{i}}=18$, and the values of $\mathrm{FOS}_{\beta=45^{\circ}}$ for $\mathrm{GSI}=17, m_{\mathrm{i}}=15$, and $\mathrm{SR}=15$ and $\mathrm{GSI}=17, m_{\mathrm{i}}=20$, and $\mathrm{SR}=15$ are 1.643 and 2.051, respectively. Second, based on the values of $\beta=53^{\circ}$ and $k_{h}=0.3, f_{k h}$ is determined to be 0.612 using Figure 9 or (19) while $f_{\beta}$ is calculated to be 0.865 using Figure 11 or (20). Finally, the upper and lower FOS values for Case 2 are calculated by using (21), and the results are 0.870 for $m_{\mathrm{i}}=15$ and 1.085 for $m_{\mathrm{i}}=20$; the final FOS is the average value which is equal to 0.978 .

In general, the FOS results obtained from the charts presented show a high degree of consistency when compared with those from Jiang et al. [28] and Slide 6.0 software. Further analysis of 1480 sets of data representing a wide range of slope geometries and rock mass parameters reveals that the discrepancy of $78.5 \%$ of data is lower than $\pm 5 \%$, and the absolute average relative error percentage (AAREP) is $3.8 \%$. Furthermore, the discrepancy exceeding $\pm 5 \%$ appears when the slope angle is larger than $60^{\circ}$ under lower GSI values and higher seismic acceleration coefficients.

\section{Discussion}

In this paper, the present investigation on pseudostatic stability analysis of rock slopes is mainly conducted based on
TABle 5: Case studies of rock slope analyzed using the proposed seismic stability charts.

\begin{tabular}{lcc}
\hline Input parameters & Case 1 & Case 2 \\
\hline$\beta\left(^{\circ}\right)$ & 50 & 53 \\
$\mathrm{GSI}$ & 40 & 17 \\
$m_{\mathrm{i}}$ & 10 & 18 \\
$k_{h}$ & 0.2 & 0.3 \\
$\sigma_{\mathrm{ci}}(\mathrm{MPa})$ & 100 & 50 \\
$\gamma\left(\mathrm{kN} / \mathrm{m}^{3}\right)$ & 28 & 24 \\
$H(\mathrm{~m})$ & 100 & 140 \\
$S R\left(\sigma_{\mathrm{ci}} / \gamma H\right)$ & 35 & 15 \\
$\quad \mathrm{FOS}$ \\
$\beta=45^{\circ}$ & 3.780 & 1.847 \\
\hline Calculated data & & \\
$\quad f_{\beta}$ & 0.906 & 0.865 \\
$\quad f_{k h}$ & 0.721 & 0.612 \\
$\quad$ Proposed charts & 2.469 & 0.978 \\
\hline FOS & & \\
$\quad$ Jiang et al.'s charts & 2.505 & 0.908 \\
$\quad$ Slide 6.0 software & 2.474 & 0.911 \\
\hline
\end{tabular}

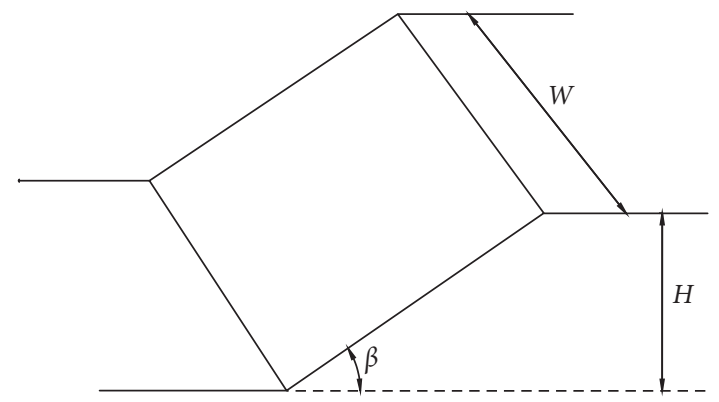

FIGURE 12: Sketch of 3D rock slope model with a limited width $W$.

the assumption of 2D plane strain analysis; thus the proposed stability charts are applicable for stability assessment of $2 \mathrm{D}$ rock slopes or $3 \mathrm{D}$ rock slopes with large ratios of $W / H$ ( $W$ is the slope width and $H$ is slope height). For the further study, the investigation of the seismic stability of a 3D rock slope (Figure 12) and providing seismic stability charts continue to pose a challenge. This is due to the fact that, as pointed by Michalowski [7], the conventional assumption of 2D plane strain may lead to a conservative result of safety reserve for a slope with a well-defined extent of the failure mechanism, as shown in Figure 12.

The effects of seismic coefficient $k_{h}$ and slope angle $\beta$ on stability of a 3D rock slope are investigated in this section, and the results are shown in Figure 13. As clearly shown in Figure 13 , the ratio $W / H$ has significant effects on the stability of the rock slope, the FOS of a 3D slope reduces sharply in conjunction with $W / H$ within $W / H \leq 2.0$, and thus the variation rules become gentle and eventually barely change when $W / H \geq 5.0$. This indicates that $2 \mathrm{D}$ solutions of FOS lead to conservative estimations of a slope and that it is essential to conduct the stability analysis of a slope in three dimensions. For a condition in which $W / H=5.0$, the FOS solutions decrease from 4.90 to 3.0 when the seismic coefficient increases from 0 to 0.3 as shown in Figure 13(a) while the FOS solutions decrease from 3.41 to 1.22 when the 


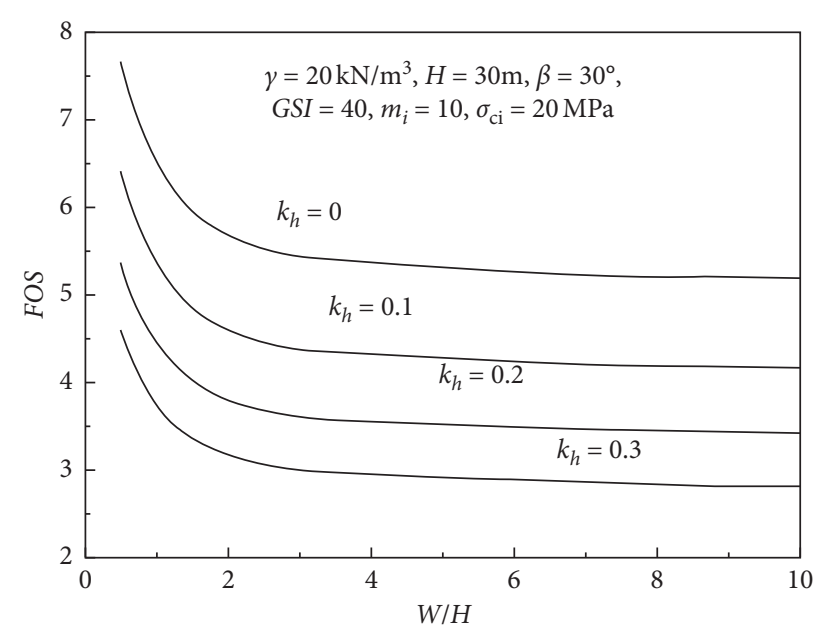

(a)

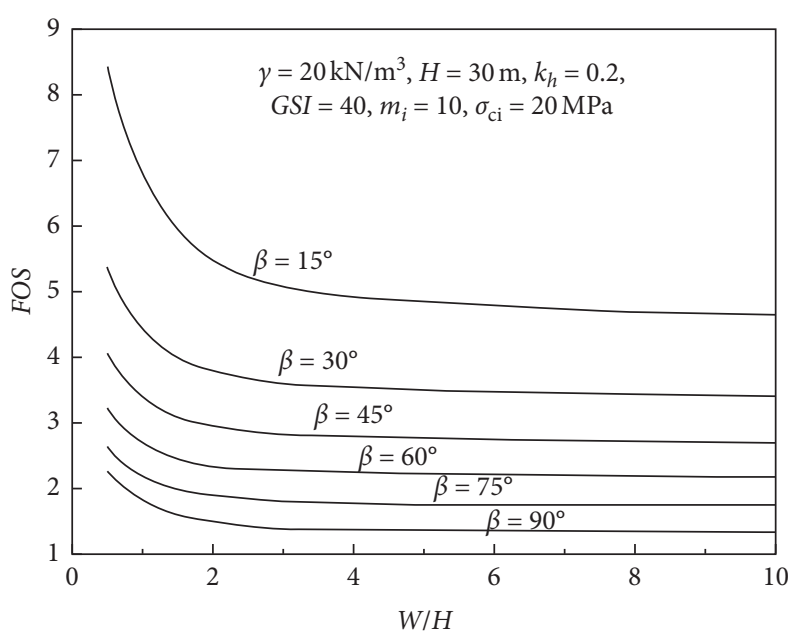

(b)

FIGURE 13: Effects of seismic coefficient $k_{h}$ and slope angle $\beta$ on 3D rock slope stability: (a) $k_{h}$, the seismic coefficient; (b) $\beta$, the slope angle.

angle of slope increases from $30^{\circ}$ to $90^{\circ}$ as shown in Figure 13(b), respectively. It is known that the seismic force and the angle of slope also exhibit nonnegligible negative influences on slope stability, and thus it is necessary to investigate the effects of seismic forces on slope stability and to provide a convenient approach to estimate the seismic stability of a 3D slope.

Therefore, our further study will aim to conduct a pseudostatic stability analysis of 3D rock slopes in HoekBrown media and develop a set of seismic stability charts based on the nonlinear Hoek-Brown strength reduction technique.

\section{Conclusions}

This paper uses the nonlinear Hoek-Brown strength reduction technique to conduct the pseudostatic stability analysis of rock slopes and proposes the seismic stability charts for rock slopes that satisfy the Hoek-Brown failure criterion. The proposed charts can be adopted for quickly evaluating the seismic stability of rock slopes in the preliminary design phase. The following main conclusions are drawn from this study:

(1) Study of the theoretical relationship between the FOS and related parameters reveals that the FOS is dependent only on the dimensionless parameter of strength ratio $\mathrm{SR}\left(\mathrm{SR}=\sigma_{\mathrm{ci}} / \gamma H\right)$ despite the magnitude of $\sigma_{\mathrm{ci}}, \gamma$ and $H$. The number of independent parameters for determining the FOS is reduced to five (SR, $m_{\mathrm{i}}$, GSI, $D, \beta$, and $k_{h}$ ) under the condition of $D=0$, which make it possible to develop the seismic stability charts for rock slopes satisfying the Hoek-Brown failure criterion. This conclusion is validated by the results of the slope cases in Tables 1 and 2 .

(2) Utilizing a simple methodology to locate the tangent of the Hoek-Brown envelope and introducing the instantaneous MC shear strength parameters make it possible to implement the nonlinear Hoek-Brown strength reduction technique by using ABAQUS 6.10 software. Based on this method, a set of stability charts is then developed as shown in Figures 6 and 7 to determine the FOS of rock slopes with slope angle $\beta=45^{\circ}$ and horizontal seismic coefficient $k_{h}$ ranging from 0.1 to 0.3 . The FOS is observed to increase obviously with the increasing values of GSI and SR. For GSI $\leq 60$, FOS increases slightly when SR increases, but the increase is remarkable for GSI $>60$. In addition, the FOS decreases with increasing $m_{\mathrm{i}}$ for high values of GSI (GSI > 60) and $k_{h}\left(k_{h} \geq 0.3\right)$, and the maximum value of $m_{\mathrm{i}}=35$ and the minimum value of $m_{\mathrm{i}}=5$ yield a narrow scope of FOS.

(3) The seismic weighting factor $f_{k h}$ and slope angle weighting factor $f_{\beta}$ are adopted to examine the effect of the horizontal seismic acceleration coefficient and the slope angle on rock slope stability. Then, the charts for determination of $f_{k h}$ (Figure 9) and $f_{\beta}$ (Figure 11) are developed for $30^{\circ} \leq \beta \leq 75^{\circ}$ and $0 \leq k_{h} \leq 0.3$, respectively. Based on these charts, values of $f_{k h}$ and $f_{\beta}$ are obtained for various values of $k_{h}$ and $\beta$. Then, in conjunction with the static stability charts for slope angle $\beta=45^{\circ}$ (Figure 6), the final FOS

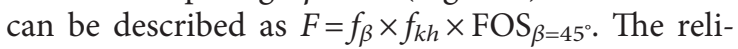
ability of the proposed charts has been investigated by three typical examples and two slope case studies, and the results of FOS obtained from the charts presented show good agreement with those from other methods, which validates the feasibility and reliability of the proposed seismic stability charts.

(4) In the present analysis for pseudostatic slope stability, the seismic effect is approximately considered as a steady loading, and only the horizontal seismic force is considered in our research. Further work will pay attention to impacts of other factors such as pore-water pressure, the vertical seismic force, and slope geomorphology on the rock slope stability. 


\section{Data Availability}

All data, models, or codes generated or used during the study are available from the corresponding author upon request.

\section{Conflicts of Interest}

The authors declare that they have no conflicts of interest.

\section{Acknowledgments}

This research was financially supported by the National Natural Science Foundation of China (51909224 and 51679197), the Natural Science Foundation Research Project of Shaanxi Province (2020JQ-920 and 2017JZ013), the Natural Science Research Project of Education Department of Shaanxi Provincial Government (19JK0910), and Scientific Research Staring Foundation for Introduced Talents of Xijing University (XJ18T05). This support is gratefully acknowledged.

\section{References}

[1] D. W. Taylor, "Stability of earth slopes," Journal of the Boston Society of Civil Engineers, vol. 24, no. 3, pp. 197-246, 1937.

[2] A. Gens, J. N. Hutchinson, and S. Cavounidis, "Three-dimensional analysis of slides in cohesive soils," Géotechnique, vol. 38, no. 1, pp. 1-23, 1988.

[3] R. Baker, "A second look at Taylor's stability chart," Journal of Geotechnical and Geoenvironmental Engineering, vol. 129, no. 12, pp. 1102-1108, 2003.

[4] A. J. Li, R. S. Merifield, and A. V. Lyamin, "Limit analysis solutions for three dimensional undrained slopes," Computers and Geotechnics, vol. 36, no. 8, pp. 1330-1351, 2009.

[5] A. J. Li, R. S. Merifield, and A. V. Lyamin, "Three-dimensional stability charts for slopes based on limit analysis methods," Canadian Geotechnical Journal, vol. 47, no. 12, pp. 1316-1334, 2010.

[6] R. L. Michalowski, "Stability charts for uniform slopes," Journal of Geotechnical and Geoenvironmental Engineering, vol. 128, no. 4, pp. 351-355, 2002.

[7] R. L. Michalowski, "Limit analysis and stability charts for 3D slope failures," Journal of Geotechnical and Geoenvironmental Engineering, vol. 136, no. 4, pp. 583-593, 2010.

[8] T. Steward, N. Sivakugan, S. K. Shukla, and B. M. Das, "Taylor's slope stability charts revisited," International Journal of Geomechanics, vol. 11, no. 4, pp. 348-352, 2011.

[9] Y. Gao, F. Zhang, G. H. Lei, D. Li, Y. Wu, and N. Zhang, "Stability charts for 3D failures of homogeneous slopes," Journal of Geotechnical and Geoenvironmental Engineering, vol. 139, no. 9, pp. 1528-1538, 2013.

[10] H. T. Eid, "Stability charts for uniform slopes in soils with nonlinear failure envelopes," Engineering Geology, vol. 168, pp. 38-45, 2014.

[11] C. Sun, J. Chai, Z. Xu, and Y. Qin, "3D stability charts for convex and concave slopes in plan view with homogeneous soil based on the strength-reduction method," International Journal of Geomechanics, vol. 17, no. 5, 2017.

[12] W. Fu and Y. Liao, "Non-linear shear strength reduction technique in slope stability calculation," Computers and Geotechnics, vol. 37, no. 3, pp. 288-298, 2010.

[13] R. Jimenez, A. Serrano, and C. Olalla, "Linearization of the Hoek and Brown rock failure criterion for tunnelling in elasto-plastic rock masses," International Journal of Rock Mechanics and Mining Sciences, vol. 45, no. 7, pp. 1153-1163, 2008.

[14] J. Shen, M. Karakus, and C. Xu, "Direct expressions for linearization of shear strength envelopes given by the generalized Hoek-Brown criterion using genetic programming," Computers and Geotechnics, vol. 44, pp. 139-146, 2012.

[15] J. Shen, S. D. Priest, and M. Karakus, "Determination of Mohr-Coulomb shear strength parameters from generalized Hoek-Brown criterion for slope stability analysis," Rock Mechanics and Rock Engineering, vol. 45, no. 1, pp. 123-129, 2012b.

[16] E. Hoek and E. T. Brown, "Empirical strength criterion for rock masses," Journal of the Geotechnical Engineering Division ASCE, vol. 106, no. GT9, pp. 1013-1035, 1980.

[17] E. Hoek, C. Carranza-Torres, and B. Corkum, "Hoek-Brown Failure Criterion-2002 edition," in Proceedings of the North American Rock Mechanics Society Meeting in Toronto, pp. 267-273, Toronto, July 2002.

[18] E. Hoek and J. Bray, Rock Slope Engineering, Institution of Mining and Metallurgy, London, 1981.

[19] P. Marinos and E. Hoek, "Estimating the geotechnical properties of heterogeneous rock masses such as flysch," Bulletin of Engineering Geology and the Environment, vol. 60, no. 2, pp. 85-92, 2001.

[20] E. Hoek, T. G. Carter, and M. S. Diederichs, "Quantification of the geological strength index chart," in Proceedings of the 47th US Rock Mechanics/Geomechanics Symposium, ARMA 13672, San Francisco, CA, USA, 2013.

[21] O. C. Zienkiewicz, C. Humpheson, and R. W. Lewis, "Associated and non-associated visco-plasticity and plasticity in soil mechanics," Géotechnique, vol. 25, no. 4, pp. 671-689, 1975.

[22] H. Zheng, D. F. Liu, and C. G. Li, "Slope stability analysis based on elasto-plastic finite element method," International Journal for Numerical Methods in Engineering, vol. 64, no. 14, pp. 1871-1888, 2005.

[23] C. Sun, J. Chai, Z. Xu, Y. Qin, and X. Chen, "Stability charts for rock mass slopes based on the Hoek-Brown strength reduction technique," Engineering Geology, vol. 214, pp. 94106, 2016.

[24] A. J. Li, R. S. Merifield, and A. V. Lyamin, "Stability charts for rock slopes based on the Hoek-Brown failure criterion," International Journal of Rock Mechanics and Mining Sciences, vol. 45, no. 5, pp. 689-700, 2008.

[25] A. J. Li, A. V. Lyamin, and R. S. Merifield, "Seismic rock slope stability charts based on limit analysis methods," Computers and Geotechnics, vol. 36, no. 1-2, pp. 135-148, 2009.

[26] A. J. Li, R. S. Merifield, and A. V. Lyamin, "Effect of rock mass disturbance on the stability of rock slopes using the HoekBrown failure criterion," Computers and Geotechnics, vol. 38, no. 4, pp. 546-558, 2011.

[27] C. Carranza-Torres, "Some comments on the application of the Hoek-Brown failure criterion for intact rock and rock masses to the solution of tunnel and slope problems," in Proceedings of the MIR 2004 - X Conference on Rock and Engineering Mechanics, G. Barla and M. Barla, Eds., pp. 285-326pp. 285-, Torino, Italy, November 2004.

[28] X.-Y. Jiang, P. Cui, and C.-Z. Liu, "A chart-based seismic stability analysis method for rock slopes using Hoek-Brown failure criterion," Engineering Geology, vol. 209, pp. 196-208, 2016.

[29] J. Shen, M. Karakus, and C. Xu, "Chart-based slope stability assessment using the generalized Hoek-Brown criterion," 
International Journal of Rock Mechanics and Mining Sciences, vol. 64, pp. 210-219, 2013.

[30] R. Baker, R. Shukha, V. Operstein, and S. Frydman, "Stability charts for pseudo-static slope stability analysis," Soil Dynamics and Earthquake Engineering, vol. 26, no. 9, pp. 813823, 2006.

[31] D. Leshchinsky and K. C. San, "Pseudo-static slope stability analysis: design charts," Journal of Geotechnical Engineering, vol. 120, no. 9, pp. 1514-1531, 1993.

[32] D. Loukidis, P. Bandini, and R. Salgado, "Stability of seismically loaded slopes using limit analysis," Géotechnique, vol. 53, no. 5, pp. 463-479, 2003.

[33] N. M. Newmark, "Effects of earthquakes on dams and embankments," Géotechnique, vol. 15, no. 2, pp. 139-160, 1965.

[34] S. A. Sepulveda, W. Murphy, R. W. Jibson, and D. N. Petley, "Seismically induced rock slope failures resulting from topographic amplification of strong ground motions: the case of pacoima canyon, California," Engineering Geology, vol. 80, no. 3-4, pp. 336-348, 2005.

[35] K. Terzaghi, "Mechanics of landslides, engineering geology (Berkley) volume," Application of Geology to Engineering Practice, Geological Society of America Bulletin, Boulder, CO, USA, 1950.

[36] F. Zhang, D. Leshchinsky, Y. Gao, and S. Yang, "Three-Dimensional slope stability analysis of convex turning corners," Journal of Geotechnical and Geoenvironmental Engineering, vol. 144, no. 6, Article ID 06018003, 2018.

[37] S. Yang, B. Leshchinsky, K. Cui, F. Zhang, and Y. Gao, "Influence of failure mechanism on seismic bearing capacity factors for shallow foundations near slopes," Géotechnique, 2020.

[38] A. J. Li, M. J. Cassidy, Y. Wang, R. S. Merifield, and A. V. Lyamin, "Parametric Monte Carlo studies of rock slopes based on the Hoek-Brown failure criterion," Computers and Geotechnics, vol. 45, pp. 11-18, 2012.

[39] California Division of Mines and Geology, Guidelines for Evaluating and Mitigating Seismic Hazards in California, Department of Conservation, Division of Mines and Geology, Sacramento, CA, USA, 1997.

[40] F. C. Dai, C. Xu, X. Yao, L. Xu, X. B. Tu, and Q. M. Gong, "Spatial distribution of landslides triggered by the 2008 Ms 8.0 Wenchuan earthquake, China," Journal of Asian Earth Sciences, vol. 40, no. 4, pp. 883-895, 2011. 